\title{
Derivation and analysis of a complete modern-date glacier inventory for Alaska and northwest Canada
}

\author{
Christian KIENHOLZ, ${ }^{1}$ Sam HERREID, ${ }^{1}$ Justin L. $\mathrm{RICH}^{1}{ }^{1}$ Anthony A. ARENDT, ${ }^{1}$ \\ Regine HOCK, ${ }^{1,2}$ Evan W. BURGESS ${ }^{1,3}$ \\ ${ }^{1}$ Geophysical Institute, University of Alaska Fairbanks, Fairbanks, AK, USA \\ ${ }^{2}$ Department of Earth Sciences, Uppsala University, Uppsala, Sweden \\ ${ }^{3}$ Alaska Science Center, United States Geological Survey, Anchorage, AK, USA \\ Correspondence: Christian Kienholz <christian.kienholz@gi.alaska.edu>
}

\begin{abstract}
We present a detailed, complete glacier inventory for Alaska and neighboring Canada using multi-sensor satellite data from 2000 to 2011. For each glacier, we derive outlines and 51 variables, including center-line lengths, outline types and debris cover. We find $86723 \mathrm{~km}^{2}$ of glacier area (27 109 glaciers $\left.>0.025 \mathrm{~km}^{2}\right), \sim 12 \%$ of the global glacierized area outside ice sheets. Of this area $12.0 \%$ is drained by 39 marine-terminating glaciers $(74 \mathrm{~km}$ of tidewater margin), and $19.3 \%$ by 148 lake- and river-terminating glaciers $(420 \mathrm{~km}$ of lake-/river margin). The overall debris cover is $11 \%$, with considerable differences among regions, ranging from $1.4 \%$ in the Kenai Mountains to $28 \%$ in the Central Alaska Range. Comparison of outlines from different sources on $>2500 \mathbf{~ k m}^{2}$ of glacierized area yields a total area difference of $\sim 10 \%$, emphasizing the difficulties in accurately delineating debris-covered glaciers. Assuming fully correlated (systematic) errors, uncertainties in area reach $6 \%$ for all Alaska glaciers, but further analysis is needed to explore adequate error correlation scales. Preliminary analysis of the glacier database yields a new set of well-constrained area/length scaling parameters and shows good agreement between our area-altitude distributions and previously established synthetic hypsometries. The new glacier database will be valuable to further explore relations between glacier variables and glacier behavior.
\end{abstract}

KEYWORDS: glacier fluctuations, glacier mapping, remote sensing

\section{INTRODUCTION}

Comprehensive glacier inventories are essential for many applications in glaciology. An inventory allows for describing the state of a glacierized region (e.g. Schiefer and others, 2008; Radić and Hock, 2010; Frey and others, 2012), while comparing multitemporal inventories allows for quantifying glacier changes (e.g. Nuth and others, 2013). Glacier inventories are also needed to extrapolate local mass-balance measurements to individual glaciers and entire regions (e.g. Arendt and others, 2006). They further provide the starting point for projections of glacier evolution (Marzeion and others, 2012; Radić and others, 2013). If glacier inventories are incomplete, up-/downscaling procedures are required (Radić and Hock, 2010; Bahr and Radić, 2012), significantly increasing uncertainty in the model results (Radić and Hock, 2011). With the increasing number of regional and global glaciological and hydrological assessments (e.g. Bliss and others, 2014), the importance of large-scale glacier inventories has grown.

A substantial portion $(\sim 12 \%)$ of the global mountain glaciers and ice caps are located in Alaska and adjacent Canada (henceforth referred to as 'Alaska glaciers'). The earliest complete maps of glacier extent were built from US Geological Survey (USGS) aerial photography acquired mostly in the late 1940s and early 1950s, and in adjacent Canada from Natural Resources Canada (NRCan) photography acquired in the 1970s and 1980s. Incorrect interpretation of seasonal snow and debris-covered ice, as well as technical blunders (e.g. systematic shifts due to lack of ground control), resulted in numerous erroneous glacier outlines. Nevertheless, digital versions of these outlines were used in many regional mass-balance assessments (e.g. Arendt and others, 2002; Larsen and others, 2007; Berthier and others, 2010). In light of the widespread glacier retreat since the first maps were compiled (Barrand and Sharp, 2010; Bolch and others, 2010; Le Bris and others, 2011), the glacier outlines further became outdated, increasing the need for a detailed, modern-date inventory for Alaska.

In 2008, the University of Alaska Fairbanks (UAF) initiated an effort to compile a complete modern-date glacier inventory for Alaska based on extensive manual digitization from satellite imagery combined with moderndate outlines from parallel studies (e.g. Bolch and others, 2010; Le Bris and others, 2011), submitted to the Global Land Ice Measurements from Space (GLIMS) database (http://glims.org, Raup and others, 2007). Since 2012, versions of the inventory have been released and used, for example, to determine glacier changes within Alaska's National Parks (Loso and others, in press). The inventory has also contributed to the global Randolph Glacier Inventory (RGl; Pfeffer and others, 2014).

Our new inventory version presented here is a major advance from previous versions. It includes glacier divides improved substantially with measured velocity fields (Burgess and others, 2013), more complete metadata and a greatly expanded set of derived attributes and datasets compared with that presented for Alaska in Pfeffer and others (2014). Our latest database includes $>50$ derived variables across 17 main categories. Among the derived datasets are a vector product that distinguishes four glacier 


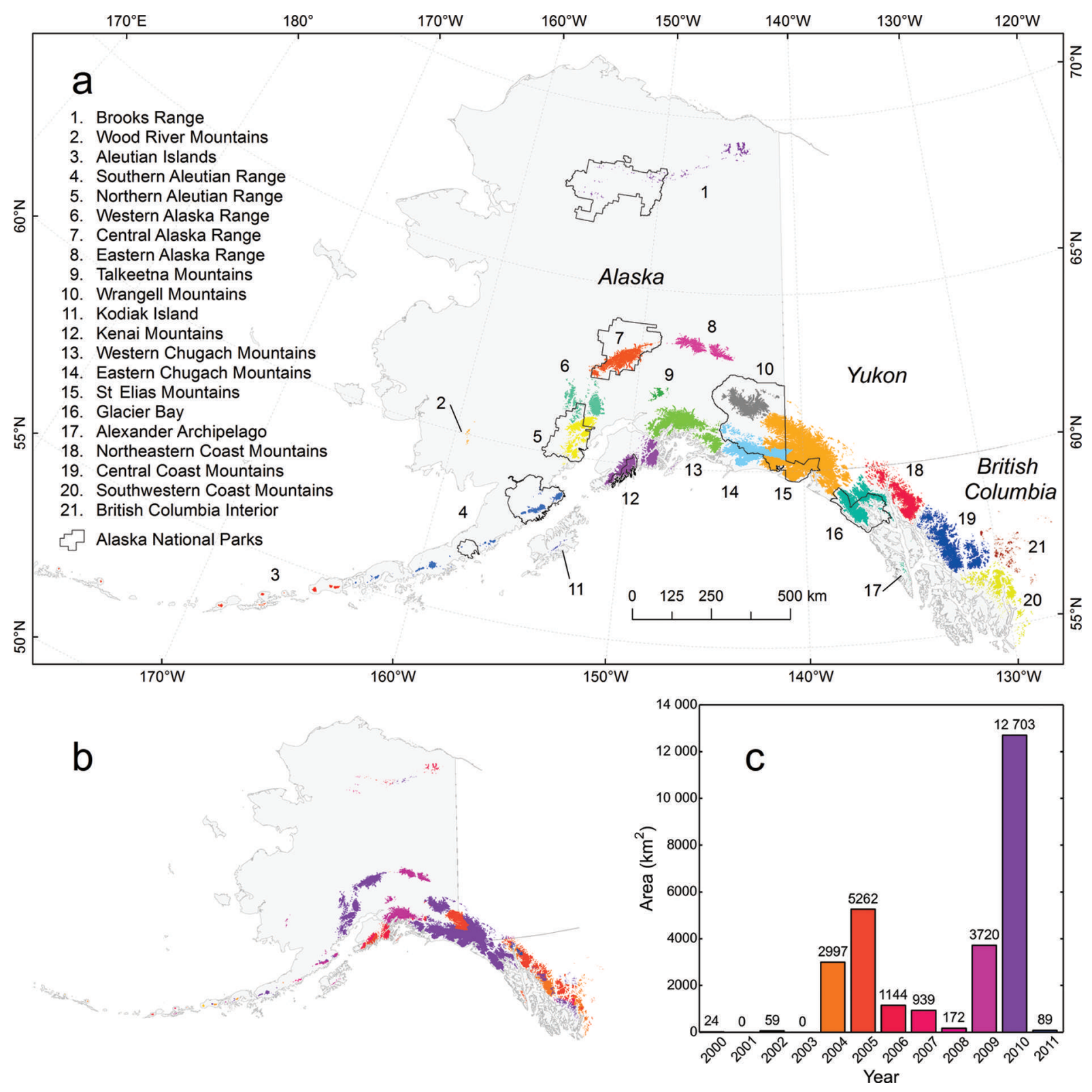

Fig. 1. (a) The 21 inventoried glacier regions, covering territory in Alaska, Yukon and British Columbia. (b, c) Map (b) and bar chart (c) illustrating the area of glaciers inventoried for each year.

margin types (glacier divides, land-terminating boundaries, lake-terminating boundaries and marine-terminating boundaries), a vector product containing glacier center lines and a gridded product representing debris cover.

The main goal of this paper is to present the applied techniques, to assess the quality of the derived products and to give an overview of the inventory statistics. In addition, we perform preliminary analyses of selected inventory variables, and derive, for example, area-length scaling relations and characteristic debris curves as a function of elevation.

\section{STUDY AREA}

Our study area, identical to RGI region 1, covers Alaska, southwest Yukon and northwest British Columbia (Fig. 1a). Glaciers cluster mainly along the mountain ranges of the southern Alaska coast, an area characterized by maritime climate and topography reaching $>5000 \mathrm{ma}$.s.l. The extreme relief is an effective barrier to the prevailing southwesterly winds (e.g. Shulski and Wendler, 2007), resulting in high annual accumulation rates and thus favorable conditions for glaciers. Further north, the climate is more continental and supports only smaller glaciers. The Brooks Range, the northernmost inventoried region, has few glaciers despite its location north of $65^{\circ} \mathrm{N}$ and elevations $>3000$ ma.s.l., due to extremely low precipitation rates (Geck and others, 2013).

We divide the inventoried glaciers into 21 subregions based on previous work (Field, 1975; Molnia, 2008) and with modifications for practical purposes. While these inventory regions group glaciers of the same mountain range or subrange together, they can extend across multiple watersheds and climate zones, which often have their boundaries over glacierized terrain (e.g. Bieniek and others, 2012). Bering Glacier is unique as it originates in the St Elias Mountains and ends in the Eastern Chugach Mountains. We allocate Bering Glacier to the Eastern Chugach Mountains, as splitting of the glacier's accumulation and ablation areas would be impractical. 
Table 1. Properties of the used satellite imagery. RGB is red, green, blue; NIR is near-infrared, SWIR is shortwave infrared and pan is panchromatic

\begin{tabular}{lccc}
\hline Sensor & Channels used & $\begin{array}{c}\text { Spatial resolution } \\
\mathrm{m}\end{array}$ & $\begin{array}{c}\text { Swath width } \\
\mathrm{km}\end{array}$ \\
\hline IKONOS & RGB, pan & 0.8 (pan), 3.2 (color) & 11 \\
Landsat 5 TM & RGB, NIR, SWIR & 30 & 185 \\
Landsat 7 ETM+ & RGB, NIR, SWIR, & 15 (pan), 30 (color) & 185 \\
\multicolumn{4}{c}{ pan. } \\
Terra ASTER & NIR, R, G & 15 & 60 \\
SPOT 4/SPOT 5 & Pan & 10 & 60 \\
& & & \\
\hline
\end{tabular}

\section{DATA}

\section{Satellite imagery}

Glacier outlines are derived from optical satellite imagery from four sources: IKONOS, Landsat, ASTER (Advanced Spaceborne Thermal Emission and Reflection Radiometer) and SPOT (Satellite Pour l'Observation de la Terre) (Table 1). To map glacier debris cover, we use Landsat 5 imagery only. The source imagery covers mostly the period 2004-10; in areas with persistent cloud coverage, it dates back as far as 2000 (Fig. 1b and c). Given its outstanding spatial resolution ( $\sim 1 \mathrm{~m})$, we favor the commercial IKONOS imagery for the outlining, which is, however, only available to us for Alaska National Parks (Fig. 1a; Loso and others, in press). Outside the National Parks, we rely mostly on orthorectified Landsat 5 and Landsat 7 imagery (Level L1G), freely available through the USGS Earth Explorer website (http://earthexplorer.usgs. gov, accessed 25 August 2013). For selected areas (Aleutians, Coast Range and Alexander Archipelago), we complement Landsat with orthorectified ASTER imagery (Level 14OTH), provided through the USGS GLOVIS (Global Visualization Viewer) website (http://glovis.usgs.gov, accessed 25 August 2013). For the Canadian part of the St Elias Range, we rely partially on orthorectified SPOT 4 and SPOT 5 imagery, downloaded from NRCan's website GeoGratis (http://www. geogratis.gc.ca, accessed 25 August 2013).

Prior to the digitization, the IKONOS images (geocoded, pansharpened true-color composites) are orthorectified using their rational polynomial coefficients and the digital elevation model (DEM) of the area covered. The already orthorectified Landsat data are combined into true- and false-color composites using the Thematic Mapper (TM)/ Enhanced TM Plus (ETM+) bands 3, 2, 1 (red, green, blue (RGB)), 5, 4, 3 (SWIR (shortwave infrared), NIR (nearinfrared), R) or 4, 3, 2 (NIR, R, G). In the case of Landsat 7, we use panchromatic band 8 to create pansharpened $15 \mathrm{~m}$ color composites. The orthorectified ASTER data are processed into false-color (NIR, R, G) composites, and in the case of SPOT $4 / 5$ we use the $10 \mathrm{~m}$ panchromatic orthoimagery as downloaded from the GeoGratis website.

\section{DEM}

We use a multi-source DEM consistent with the time span of our inventory (Fig. 2a). This DEM, compiled by Kienholz and others (2014), is based on four different DEM products: a DEM derived from airborne interferometric synthetic aperture radar (InSAR), the Shuttle Radar Topography Mission (SRTM) DEM, SPOT DEMs and the global ASTER DEM version 2 (ASTER GDEM2). Both the InSAR and the SRTM

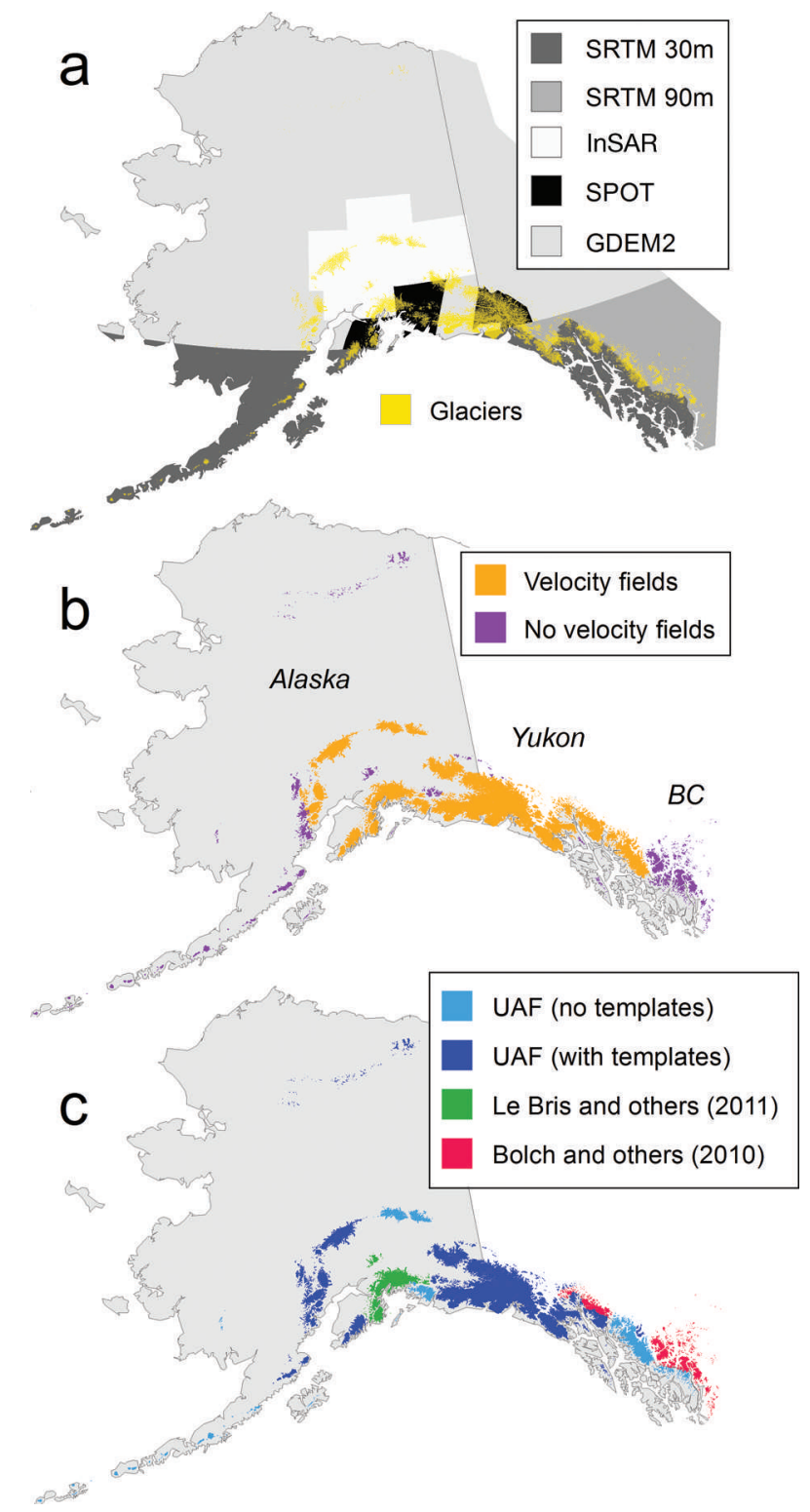

Fig. 2. (a) DEM sources with glaciers in yellow. (b) Coverage of velocity fields used for mapping ice divides. (c) Outline sources. Note that the digitization of the UAF outlines was often guided by existing outlines used as templates. The extents of the Bolch and others (2010) and Le Bris and others (2011) outlines show where we used their outlines without, or with only minor, changes.

DEM are interferometrically derived from radar data: the InSAR DEM from airborne X-band data obtained in summer 2010 (http://ifsar.gina.alaska.edu, accessed 10 December 2013), and the SRTM DEM from spaceborne C-band data obtained in February 2000 (Farr and others, 2007). The SPOT DEM and the ASTER GDEM2 are based on photogrammetric analysis of stereo imagery from the high-resolution stereo instrument on board the SPOT satellite (Korona and others, 2009) and the ASTER instrument on board the Terra satellite (Tachikawa and others, 2011). Based on previous quality assessments (e.g. Frey and Paul, 2012) and our own inspections, we prefer the radar-derived DEMs to those derived from optical imagery. In the case of overlapping SPOT and ASTER DEMs, preference is given to the SPOT DEM. While the DEM quality is good overall, it can be poor in areas where both the underlying SPOT and GDEM contain blunders (e.g. due to clouds). In total, $14 \%$ of the glacierized 
area is covered by the InSAR DEM, $36 \%$ by the SRTM, $28 \%$ by SPOT and $22 \%$ by the ASTER GDEM (Fig. $2 \mathrm{a}$ ).

\section{Velocity fields}

We use remote-sensing-derived glacier velocity fields to map glacier divides. The velocity fields are derived using offset tracking and Japanese Advanced Land Observing Satellite (ALOS) Phased Array-type L-band synthetic aperture radar (PALSAR) data acquired between 2007 and 2011 (Burgess and others, 2013), consistent with the time range of our inventory. The ALOS data cover $\sim 75 \%$ of the glacierized area (Fig. 2b). As measured velocity fields are spatially discontinuous (e.g. due to decorrelation in the imagery used), the actual coverage is $\sim 50 \%$ of the glacierized area. Regions without coverage include the Brooks Range, the Aleutian Islands and the southern part of the Coast Mountains. To facilitate mapping of the glacier divides, the initial velocity vectors are converted into streamlines, a set of lines tangent to the glacier velocity vectors.

\section{Outlines from previous studies}

This study directly incorporates outlines from two previous studies, available through the GLIMS database (Raup and others, 2007). The outlines provided by Bolch and others (2010) cover $\sim 30000 \mathrm{~km}^{2}$ in British Columbia and Alberta, $\sim 18000 \mathrm{~km}^{2}$ of which is in our study area; those of Le Bris and others (2011) cover $\sim 16000 \mathrm{~km}^{2}$ in western Alaska and lie completely within our study area. Both studies rely on Landsat imagery and employ R/SWIR band ratioing (TM3/ TM5) with manual threshold selection to obtain initial glacier complexes. Le Bris and others (2011) use an additional blue threshold (TM1) to improve the results in areas with cast shadows. Filtering is employed to remove isolated misclassified debris cells surrounded by glacier ice. Debris-covered ice, water bodies and perennial snow are improved manually after the automated steps.

\section{METHODS}

\section{Glacier outlines}

Because clouds, debris cover and perennial snow are common in Alaska, our 'UAF outlines' (i.e. outlines other than those adopted from Bolch and others (2010) and Le Bris and others (2011); Fig. 2c) are not directly based on automated classification algorithms. We often use available ice outlines as templates and modify them manually based on the best available satellite imagery. Our template outlines in Alaska are primarily from 1:63 360 USGS maps compiled between the late 1940s and the 1970s. In the Yukon, they stem from the 1:50000 National Topographic Data Base, Canada, mainly reflecting the 1980s. Digital versions of these outlines are provided by Berthier and others (2010), B. Manley (unpublished data) or downloaded from the corresponding websites (http://earthexplorer.usgs. gov, ftp://ftp2.cits.rncan.gc.ca). In some areas (e.g. Eastern Alaska Range and parts of the Coast Mountains; Fig. 2c), we digitize the glacier complexes from satellite imagery without using template outlines.

The manual editing is guided by GLIMS standards (Raup and Khalsa, 2007). Importantly, we consider debris-covered ice as part of the glacierized area unless it is clearly detached from the main glacier. As debris-covered ice is challenging to delineate, we often consult additional data, including imagery from other dates (having different shading) as well as contours and shaded relief maps derived from the DEM (facilitating the interpretation of landforms). Such an approach helps to improve the quality of the outlines, but does not guarantee full consistency or even the correct solution. The analysis of radar interferograms has shown potential for the derivation of debris-covered glacier areas (Atwood and others, 2010; Frey and others, 2012). However, these methods require extensive processing of proprietary radar imagery, preventing their application in this study.

Following the digitization, we subdivide the glacier complexes into individual glaciers, using mainly the algorithm described in Kienholz and others (2013). This algorithm splits glaciers along watershed boundaries which approximate flow divides provided the DEM is accurate. Glacier complexes that drain into multiple termini are treated as separate glaciers, even if historically they have been treated as one glacier. This facilitates their allocation to individual watersheds (the termini may reach into different watersheds), the assignment of glacier type variable (e.g. one terminus may be land-terminating while the other may be lake-terminating) and the application of center-line algorithms. Some glacier complexes are manually split into multiple glaciers even if they drain into one common terminus. This occurs, for example, if the dynamic interaction is minimal (e.g. if there is a large area of stagnant, debris-covered ice between the glaciers) or if the glaciers show different dynamic behavior (e.g. surging and nonsurging). Studies requiring fewer partitions between glaciers (e.g. regional mass-balance extrapolations) can be accommodated by merging glacier polygons.

\section{Combination of outline sources}

There is $\sim 20 \%$ overlap between outlines compiled at UAF and those obtained by Bolch and others (2010) and Le Bris and others (2011), in which case we here give preference to the UAF outlines. After combining the outline sources (Fig. 2c), we check the glacier divides visually using streamlines derived from the ALOS-PALSAR velocity fields. Streamlines approximate the two-dimensional projections of ice trajectories, which facilitates large-scale visual checks (Fig. 3a). While checking the divides, we also check for remaining blunders (e.g. perennial snow misclassified as glaciers, misclassified debris-covered areas) and make manual adjustments if necessary. Finally, we apply a minimum threshold of $0.025 \mathrm{~km}^{2}$ throughout the inventory.

\section{Center lines}

Automatic generation of glacier center lines provides a consistent means for determining location and length of glacier branches. These data are utilized for conducting length change assessments (e.g. Winsvold and others, 2014), planning airborne monitoring programs (e.g. snow radar; McGrath and others, 2013) and objectively measuring branch topology (e.g. Sevestre and others, 2013). For each glacier $>0.1 \mathrm{~km}^{2}$, we calculate center lines semiautomatically, using a cost-grid-least-cost-route approach (Kienholz and others, 2014). This approach identifies center lines between glacier heads and termini by calculating least-cost routes on a cost grid with highest values along glacier boundaries and in higher glacier reaches. In an additional step, the initial center lines are split into center lines that cover individual branches only. While we largely 

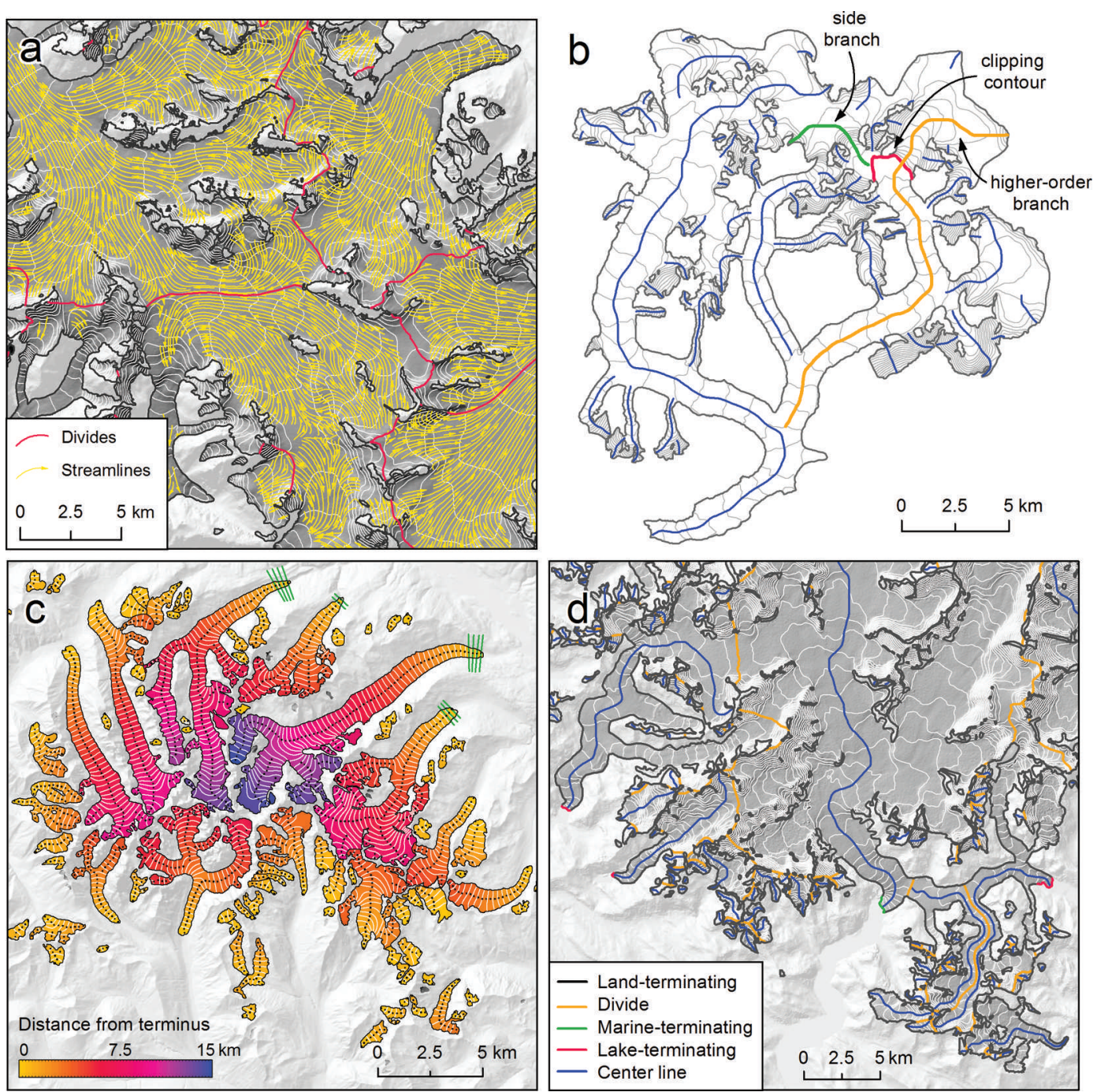

Fig. 3. (a) Streamlines and glacier divides overlaid on glaciers of the Juneau Icefield area (Coast Mountains). White lines correspond to $50 \mathrm{~m}$ contours derived from the SRTM DEM. (b) Illustration of the approach to split the center lines into individual branches. The clipping contour (shown in red) is the last contiguous contour between the higher-order branch (orange) and its side branches (one shown in green). The side branches are cut along the clipping contour, and only the part in contact with the glacier head is retained. (c) Interpolated distance grid for selected glaciers of the Central Alaska Range. The color-coded grid and the white $250 \mathrm{~m}$ contours indicate the approximate distance from each glacier's gridcell to its terminus. The black dots illustrate the evenly spaced points along the center lines used to interpolate the distance grid through spline interpolation. The green lines are the cross-profiles used to support the spline interpolation in the terminus area. (d) Outline types and center lines derived for a subset of the Coast Mountains.

follow the steps in Kienholz and others (2014), we apply a different method to derive the final center lines (Fig. 3b). Kienholz and others (2014) use one area-dependent buffer distance per glacier to split the center lines, which does not account for the different branch widths typically occurring on a glacier (see their step 3). Here, we define the centerline extent in the sense that center lines end as they reach an elevation band in continuous contact with the next higher-order branch. In practice, we split the center lines along the uppermost continuous elevation contour between the center line and the connected higher-order branch. This contour is selected from a set of $5 \mathrm{~m}$ contours calculated for each glacier.

\section{Derived variables}

To quantify a wide range of glacier properties, we acquire a comprehensive set of inventory variables. Table 2 presents the full list of derived variables, while the following subsections focus on the derivation of some key variables.

\section{Distance grid and area-length distribution}

Many glacier observations (e.g. surface velocities; Burgess and others, 2012) are best expressed with distance along flow as the independent variable. While center lines provide this information for one-dimensional applications (i.e. along approximated flowlines), higher-dimensional applications (e.g. distributed modeling of debris cover, automated determination of glacier length changes) may benefit from a fully distributed distance grid. We here derive a distance grid for each glacier using the distance information conveyed by our center lines. In an initial step, we sample the center lines ( $100 \mathrm{~m}$ sampling distance) to obtain distance information at discrete points. We then fit a continuous surface through these points by applying a spline interpolation (Franke, 1982). By using glacier outlines as interpolation boundaries, we prevent interpolation across branches. To improve the interpolated surface in the terminus area, we add additional points along cross-profiles, with the same distance information as the point on the 
Table 2. List of derived inventory variables. The climate data are derived from the PRISM dataset (Daly and others, 1994)

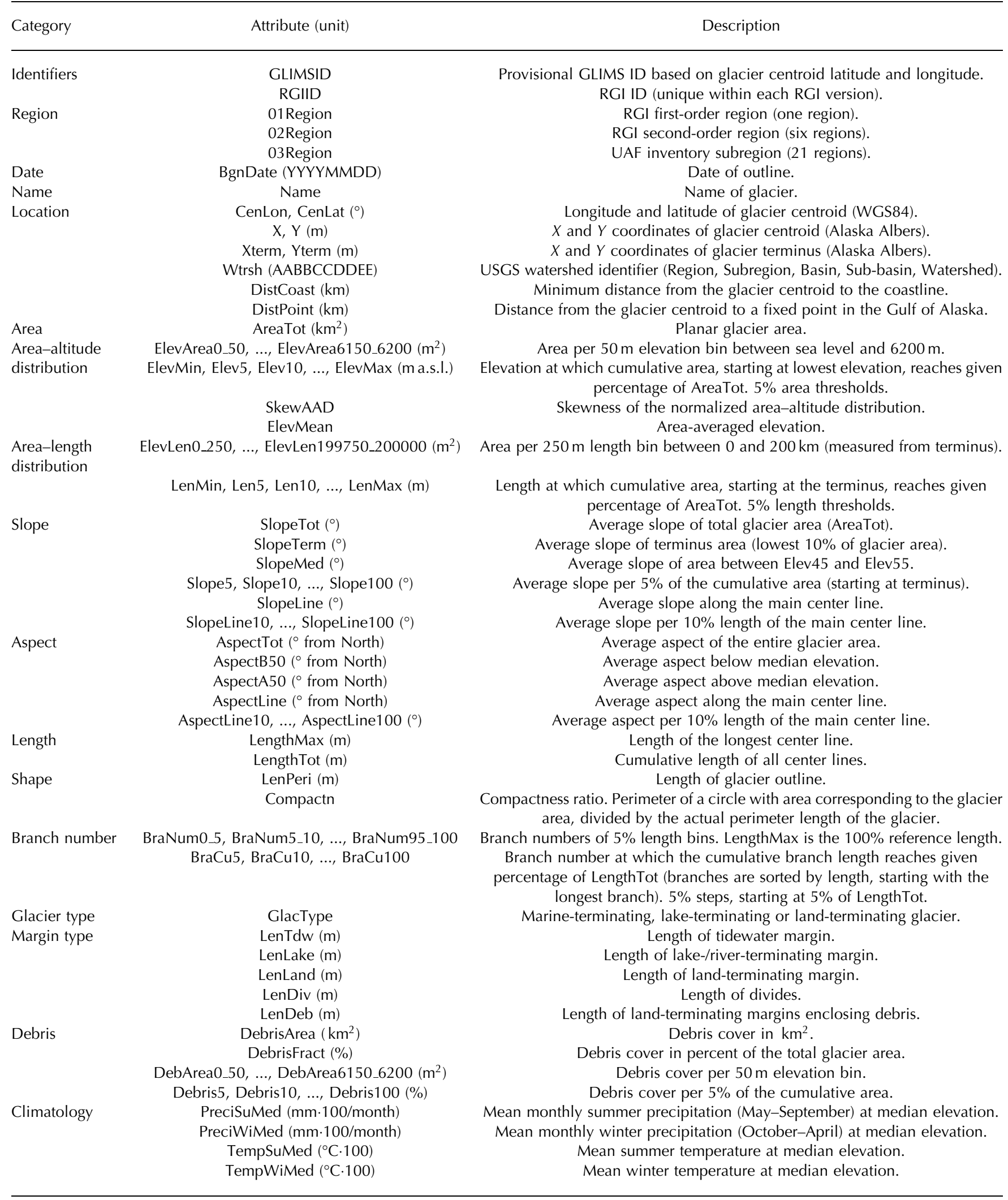

center line (Fig. 3c). To calculate the area-length distributions, we adopt two approaches: non-normalized and normalized regarding length (Table 2).

\section{Slope and aspect}

Glacier aspects and slopes are commonly examined as controls on glacier mass balance and dynamic adjustment (e.g. Anderson and Mackintosh, 2012; Huss, 2012; Geck and others, 2013). Spatial sampling strategies vary among studies, ranging from using glacier-averaged to localized values only. Here we calculate glacier-averaged slopes and aspects according to Paul and others (2009) and complement them with slopes and aspects averaged over the area above and below the median glacier elevation, which 
represent roughly the accumulation and ablation area. We also record the mean slopes per 5\% hypsometry bin, which can be averaged to obtain slopes over larger hypsometry ranges (e.g. the mean slope of the glacier tongue, defined as the mean slope of the lowermost $10 \%$ in Huss (2012)). Finally, we calculate slopes and aspects along the entire glacier center lines as well as for sub-segments that make up $10 \%$ of the total center-line length (see Supplementary Materials (http://www.igsoc.org/hyperlink/14j230_supp.pdf) for the equations).

\section{Debris}

Maps of debris cover are a key requirement to assess the effect of debris cover on glacier mass balance (e.g. Reid and Brock, 2010; Anderson and Mackintosh, 2012), which is not currently well understood, at least on regional scales (e.g. Berthier and others, 2010; Kääb and others, 2012). We here use the Landsat 5 band ratio TM4/TM5 with a threshold of 1.8 to differentiate bare ice from debris-covered ice (Paul and others, 2004). To address small, erroneous debris patches and misclassified supraglacial lakes, we apply two filters: one that removes area classified as debris-covered with a surface area $<5000 \mathrm{~m}^{2}$, and a second one that fills holes within the debris-covered area that are $<10000 \mathrm{~m}^{2}$ in size. After applying the filters, we combine the debris layers from individual scenes into one Alaska-wide dataset. Areas of overlap between scenes are manually clipped, keeping the debris maps of higher quality and/or later date of satellite image acquisition. The combined map is checked visually, and the remaining erroneous patches of debris (e.g. in clouded areas) are removed. The final grid is used to determine each glacier's overall debris cover, as well as the debris cover per $50 \mathrm{~m}$ and $5 \%$ bin of the area-altitude distribution. Debris maps are generated for nearly all of our study area, but due to cloud cover they are only partially generated for the Brooks Range and Southern Aleutian Range. Some of the smaller regions (Wood River Mountains; Aleutian Islands; Kodiak Island; Alexander Archipelago) lack coverage entirely, but they make up only $0.6 \%$ of the total glacierized area.

\section{Glacier type}

Frontal ablation (i.e. mass loss predominantly by calving and subaqueous melting; Cogley and others, 2011) is a potentially large contributor to glacier mass loss. The identification of glaciers with frontal ablation is thus desirable, for example, to better accommodate the needs of mass-balance studies (e.g. Arendt and others, 2006). We here distinguish land-, marine- and lake/river-terminating glaciers based on our own visual inspection of optical satellite imagery and DEMs as well as previous work (Molnia, 2008; McNabb and Hock, 2014). For this study, a glacier is classified as marine-terminating if it reaches tidewater at the time of the used image. Glaciers ending on an outwash plain close to tidewater (e.g. Taku Glacier) are considered land-terminating even if they are subject to the tidewater glacier cycle (Meier and Post, 1987). A glacier is classified as lake-terminating if major parts of its terminus reach a proglacial lake or river or if the imagery suggests substantial calving through marginal lakes.

\section{Margin type}

In addition to the overall glacier type, we classify the actual glacier margins, which aids, for example, partitioning of mass-balance components or the estimation of outline uncertainties. Aside from lake- and marine-terminating margins, we distinguish land-terminating margins and flow divides (Fig. 3d). The flow divides are derived from the original glacier outlines through an automated five-step workflow (Fig. S1 (available online at http://www.igsoc.org/ hyperlink/14j230_supp.pdf)). The resulting lines are then manually updated with the lake- and marine-terminating boundaries as derived from the satellite imagery. We use the final product to determine the lengths of the four margin types for each glacier. By intersecting the land-terminating outlines with the debris layer, we roughly approximate the outlines enclosing debris, a quantity that is used to estimate the outline uncertainties. Compared to flux-gate estimates, our lake- and tidewater lengths will be systematically longer, as our margins do not necessarily run perpendicular to the glacier flow direction.

\section{Climatology}

For each glacier, we derive a basic climatology, consisting of mean monthly summer (May-September) and winter (October-April) precipitation and temperature at the median glacier elevation, using the median elevation as a surrogate for the equilibrium line (Braithwaite and Raper, 2010). The climatologies are derived from the Parameter elevation Regressions on Independent Slopes Model (PRISM) dataset, which applies an analytical climate-elevation regression to distribute station precipitations and temperatures over a regularly spaced grid (Daly and others, 1994). Here we use monthly gridded datasets with a spatial resolution of $2000 \mathrm{~m}$, representing the period 1971-2000. Despite its coarse spatial resolution and considerable uncertainties in areas without weather stations, this climatology provides first-order climate information that aids mass-balance related studies (e.g. Braithwaite and Raper, 2007).

\section{Watersheds}

We allocate all glaciers in Alaska to $>500$ glacierized USGS fifth-level watersheds that make up 26 basins in six regions (agdcftp.wr.usgs.gov/pub/projects/AWSHED, accessed 25 April 2014). The implementation consists of a spatial query that pairs each glacier terminus with the watershed in which it lies. The glacierized portions of the watersheds are automatically updated to match the divides of our glaciers. These watersheds allow the quantification of the glacierized areas per watershed, which will allow a better assessment of runoff changes in the future.

\section{UNCERTAINTIES}

The following subsections assess the uncertainties in the glacier outlines, the center lines and the debris layer. For other variables, we assume typical uncertainties derived in previous work (e.g. Frey and Paul, 2012).

\section{Outlines}

Inaccuracies in the outlines

To assess outline inaccuracies, we first adopt the approach introduced by Pfeffer and others (2014). Here the error $e$ $\left(\mathrm{km}^{2}\right)$ of each glacier is given as a function of the glacier area $s\left(\mathrm{~km}^{2}\right)$,

$$
\mathrm{e}=k \mathrm{e}_{1} s^{p}
$$

where $p(0.7), e_{1}(0.039)$ and $k$ (3.0) are empirically derived 


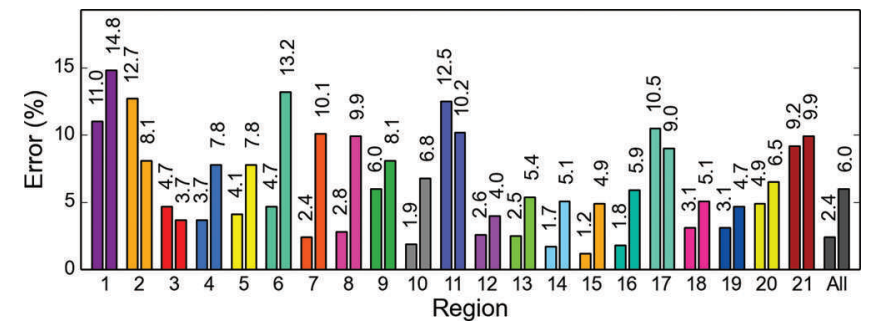

Fig. 4. Percentage errors for the 21 subregions and all Alaska glaciers, using Eqns (1) (with $k=3$, bar on left) and 2 (bar on right).

exponents and coefficients based on previously published estimates of area measurement uncertainties (Pfeffer and others, 2014). In addition, we employ an approach that is based directly on the length of the glacier margins, along which the outlining errors occur. This approach is adapted from previous work (e.g. Rivera and others, 2007; Krumwiede and others, 2014) with the error e $\left(\mathrm{km}^{2}\right)$ given by

$$
\mathrm{e}=\sum_{i=1}^{l} l_{i} w_{i}
$$

where $I_{i}(\mathrm{~km})$ is the length of the glacier margin of type $i$, and $w_{i}(\mathrm{~km})$ is the mismatch between the true outlines (generally unknown) and the digitized outlines for margin type $i$. For clean ice boundaries, we use a $w$ of $\pm 15 \mathrm{~m}$ (Paul and others, 2013) while we increase the uncertainty to $\pm 150 \mathrm{~m}$ for outlines enclosing debris (Frey and others, 2012). For simplicity, we use the same uncertainties $w_{i}$ for all satellite sensors. Also, we do not account for the fact that glacier margins resemble fractals, with lengths $l_{i}$ varying with the degree of generalization applied. Finally, we recognize that the error from Eqn (2) can deviate from the corresponding error obtained through margin buffering (suggested by Paul and others, 2013), but with differences that tend to be relatively small for hand-digitized, smooth outlines.

Summing up the glacier-specific errors from Eqns (1) and (2) across our study region assumes systematic (i.e. fully correlated) outlining errors. Over large scales, outlining errors are likely not fully correlated, thus at least partially averaging out, which is addressed statistically by combining the uncorrelated errors in quadrature. However, determining realistic region-wide errors is hampered by the difficulty

Table 3. Area errors for all Alaska glaciers based on Eqns (1) and (2) and five assumptions regarding error correlation. Equation (1) is applied on the glacier complexes rather than individual glaciers, accounting for errors that sum to zero if both sides of the divide are included. Likewise, glacier divides $(11687 \mathrm{~km}, 5.8 \%$ of the margins) are excluded in the case of Eqn (2)

\begin{tabular}{lcc} 
Correlation scenario & \multicolumn{2}{c}{ Error estimates } \\
& Eqn (1) & Eqn (2) \\
& $\mathrm{km}^{2}(\%)$ & $\mathrm{km}^{2}(\%)$ \\
\hline 1. Errors fully correlated & $2072(2.4)$ & $5183(6.0)$ \\
2. Four independent regions & $1353(1.6)$ & $3648(4.2)$ \\
3. 21 independent regions & $579(0.7)$ & $1657(1.9)$ \\
4. 27109 independent glaciers & - & $203(0.2)$ \\
5. $\sim 200000$ indep. 1 km segments & - & $12(0.01)$
\end{tabular}
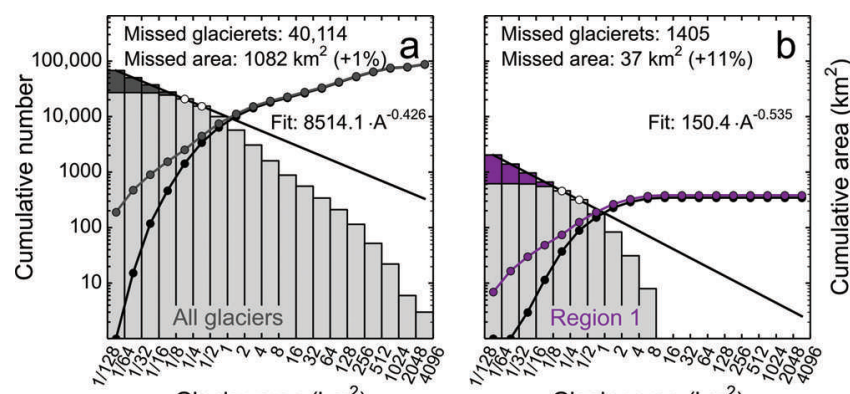

Glacier area $\left(\mathrm{km}^{2}\right)$

Glacier area $\left(\mathrm{km}^{2}\right)$

Fig. 5. Missed glacierets for (a) all Alaska and (b) the Brooks Range glaciers, assuming the power law size distribution between the $0.125-0.25$ and the $0.25-0.5 \mathrm{~km}^{2}$ size classes down to the smallest size class. The light-gray histogram shows the cumulative frequency distribution of glacier size, while the dark-gray/purple histogram indicates potentially missed glacierets. The black line shows the power law fit. Dotted lines show the cumulative glacier area with and without the potentially missed glacierets included.

of defining the spatial scales at which the errors become uncorrelated. Therefore, we present errors for all Alaska glaciers based on five potential error correlation scenarios (Table 3). Scenario 1 is the most conservative, assuming fully correlated errors. Scenario 2 distinguishes four regions that have outlines from different imagery and techniques: UAF high resolution (i.e. IKONOS), UAF low resolution (mostly Landsat), outlines from Bolch and others (2010) and from Le Bris and others (2011). This scenario then assumes fully correlated errors within each region, but uncorrelated errors among the four regions. The progressively less conservative scenarios 3,4 and 5 treat the errors from the 21 inventory regions, the 27109 glaciers and the $\sim 200000$ $1 \mathrm{~km}$ outline segments, respectively, as uncorrelated.

The spread in the resulting total errors is substantial, ranging from $0.01 \%$ to $6.0 \%$ of the total glacierized area. We here choose the most conservative scenario, 1, recognizing that the final Alaska-wide errors might be lower. Figure 4 illustrates the corresponding errors for the 21 subregions and for all of Alaska.

\section{Omission errors}

Equations (1) and (2) include errors related to inaccurate mapping, but do not account for omission errors. To obtain a first-order estimate for such omission errors, we apply a downscaling approach introduced by Bahr and Radić (2012) and applied by Pfeffer and others (2014), which suggests a power law size distribution down to the smallest glacier sizes. Assuming that the power law between the 0.125-0.25 and the $0.25-0.5 \mathrm{~km}^{2}$ size classes applies to the smallest size class (here $1 / 128 \mathrm{~km}^{2}$ ), we miss $1062 \mathrm{~km}^{2}(1.2 \%)$ of ice area, constituted by $\sim 40000$ glacierets (Fig. 5a). The fraction of missed area is higher for regions that comprise small glaciers only. In the case of the Brooks Range (largest glaciers $<10 \mathrm{~km}^{2}$ ), the potentially missed glacier area corresponds to $11 \%$ of the currently inventoried area (Fig. 5b; estimates for all regions are shown in Fig. S2 (http:// www.igsoc.org/hyperlink/14j230_supp.pdf)). Our power law (fitted between the $0.125-0.25$ and the $0.25-0.5 \mathrm{~km}^{2}$ size classes) is less steep than a power law fitted over larger size ranges (Fig. 5). We choose this flatter power law by considering that all our cumulative curves level out towards smaller size classes (even in regions digitized from high- 
resolution IKONOS imagery), indicating that the power law obtained over larger size classes may not apply to smaller glacier classes.

\section{Outline comparison}

In addition to the above formal error estimates, we compare two sets of outlines in the Northern Aleutian Range region, which includes $>1600$ glaciers, both debris-covered and largely debris-free (Fig. S3a (http://www.igsoc.org/ hyperlink/14j230_supp.pdf)). The first set of outlines, compiled by Le Bris and others (2011), is derived semiautomatically from a 2007 Landsat scene. The second set uses these outlines as a template, but is manually adapted to match IKONOS imagery taken between 2006 and 2010. Both datasets have identical glacier divides so that area differences directly reflect differences in glacier outlining (which in turn depend on the interpretation of the GLIMS guidelines, the techniques applied (automated vs manual) and the imagery used (high vs low resolution)). While the IKONOS-derived outlines for the entire region make up $2878.5 \mathrm{~km}^{2}$, the Landsat-derived outlines have an area that is $9.8 \%$ lower $\left(2597.4 \mathrm{~km}^{2}\right)$. The IKONOS-derived outlines are systematically larger than the Landsat-derived outlines, with largest relative area differences for the smallest glaciers (Fig. 6a and b). The absolute area differences increase with glacier outline lengths (Fig. 6b). Dividing the area difference of $281.1 \mathrm{~km}^{2}$ by the total IKONOS outline length $(9008 \mathrm{~km}$, excluding divides) yields an average systematic difference of $31.2 \mathrm{~m}$ along the entire perimeter. To distinguish between outlines enclosing clean ice $(8349 \mathrm{~km})$ and debris $(659 \mathrm{~km})$, we solve Eqn (2), obtaining differences of $14.5 \mathrm{~m}$ and $237.6 \mathrm{~m}$, respectively. Assuming both datasets contribute similar magnitudes to the total error (summed in quadrature (e.g. Williams and others, 1997)), we obtain uncertainties of $10.25 \mathrm{~m}$ (clean ice) and $168 \mathrm{~m}$ (debris), in approximate agreement with $w$ of \pm 15 and $\pm 150 \mathrm{~m}$ used to assess our regional errors.

We note that the two compared datasets likely show two end-member interpretations of the GLIMS guidelines, with conservative (Le Bris and others, 2011) and liberal (this study) inclusion of debris-covered sections. Unlike in previous studies (e.g. Bolch and others, 2010; Paul and others, 2013) the two compared datasets are also not fully independent (Landsat outlines are used as a template for the IKONOS outlines) and are from imagery taken up to 3 years apart. Despite these constraints, this large-scale comparison highlights the difficulties associated with delineating debriscovered ice and shows that $\sim 10 \%$ area differences can be expected, even on a regional scale. This supports the choice of a conservative error correlation scenario for the regional error estimate (Table 3).

\section{Center lines}

Machguth and Huss (2014) derived glacier lengths for Alaska using the same outlines and DEM as this study, but a different method. As part of their study, they compared the center-line lengths obtained from the two methods. For large glaciers $\left(>10 \mathrm{~km}^{2}\right)$, they find close agreement between the two approaches, with length errors $<5 \%$. Discrepancies increase towards smaller size classes, with potential length errors on the order of $20 \%$ for the smallest size class $(0.1-$ $\left.0.5 \mathrm{~km}^{2}\right)$. We here adopt these numbers and express potential length errors $e_{l}(\mathrm{~km})$ as a continous function of
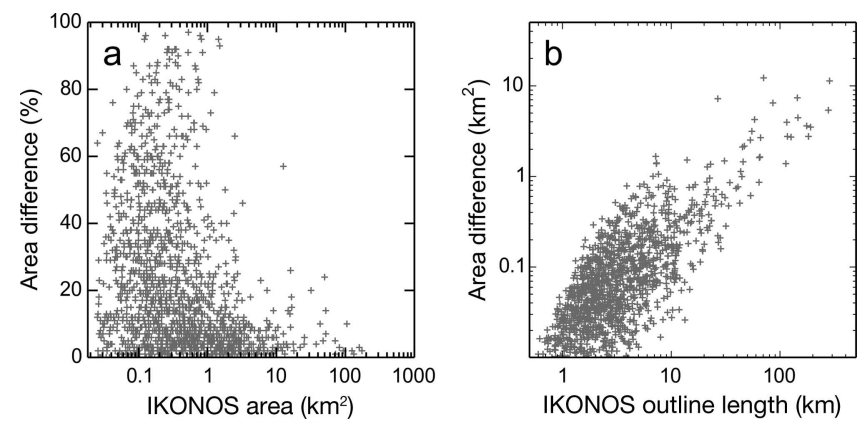

Fig. 6. (a) Relative area difference as a function of the IKONOS area. (b) Absolute area difference as a function of the IKONOS outline length.

the glacier area $s\left(\mathrm{~km}^{2}\right)$ using the power law,

$$
\mathrm{e}_{l}=l c s^{p},
$$

where $I$ is the glacier length $(\mathrm{km}), c=0.1$ and $p=-0.3$. Coefficient and exponent are chosen to obtain $20 \%$ length errors at $0.1 \mathrm{~km}^{2}$ and $5 \%$ errors at $10 \mathrm{~km}^{2}$ (resulting in $2.5 \%$ and $1.25 \%$ errors at 100 and $1000 \mathrm{~km}^{2}$, respectively). This equation does not account for possible systematic differences which may occur towards smaller size classes, as indicated by Machguth and Huss (2014). Also, it does not account for varying DEM quality, which can locally reduce the accuracy of the derived center-line lengths.

\section{Debris}

Based on visual inspections, we expect the debris percentages per glacier to be within $5 \%$ of the actual value, but with uncertainties that can greatly increase towards smaller glaciers. Overall, the debris cover is likely underestimated for two main reasons. Seasonal snow in the used satellite imagery masks some of the debris if the snowline lies below the glacier equilibrium line. Also, clouded areas are masked out so that debris is missed in those areas. The applied filters have two opposing effects: they tend to reduce debris in areas with sparse debris cover, while increasing debris in areas where debris cover is dense. While these effects partially cancel out over larger regions, the number of glaciers with low debris percentages is biased negatively while the number of glaciers with high debris cover is biased positively.

\section{INVENTORY CHARACTERISTICS}

The following subsections describe the main inventory characteristics and examine relationships among some of the derived variables. While this work aims at giving an overview, the derived data allow for more in-depth analyses in future studies.

\section{Number, area, length}

The Alaska glacier inventory (summarized in Table 4) comprises 27109 glaciers (585 named) with a total area of $86723 \mathrm{~km}^{2}$. Glaciers make up $\sim 3.5 \%$ of Alaska's total area, which is less than previously estimated (e.g. 5\%; Molnia, 2008).

The largest contiguous ice mass in Alaska exceeds $30000 \mathrm{~km}^{2}$ in area, spanning parts of the St Elias and Eastern Chugach Mountains and feeding the largest glaciers in our 


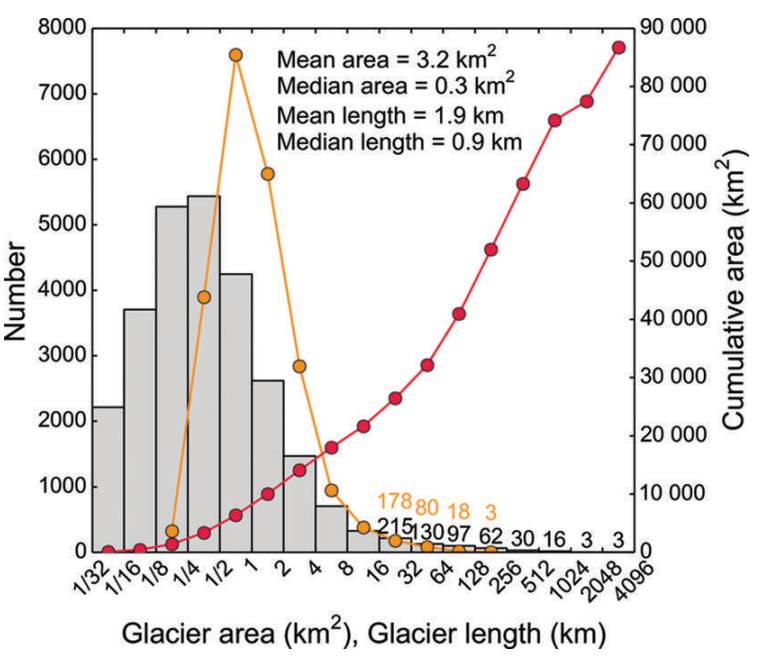

Fig. 7. (a) Frequency distributions of glacier area (histogram, left axis) and length (orange line, left axis). The cumulative glacier area (right axis) is shown in red.

inventory (Fig. S4 (http://www.igsoc.org/hyperlink/ 14j230_supp.pdf)): Seward (flowing into the Malaspina piedmont), Bering and Hubbard glaciers. While Seward Glacier is the largest of these, it is only the second longest $(137 \mathrm{~km})$, behind Bering Glacier $(197 \mathrm{~km})$ and ahead of Hubbard Glacier $(131 \mathrm{~km})$. Combining glaciers with common termini into one glacier system, the Malaspina Glacier system is the largest $\left(4640 \mathrm{~km}^{2}\right)$, followed by the Bering Glacier system $\left(4300 \mathrm{~km}^{2}\right)$. Unlike previous studies (e.g. Beedle and others, 2008), we distinguish Bering Glacier from the unnamed middle lobe of the Bering Glacier system due to its distinct surge dynamics (Burgess and others, 2012). This explains why Bering Glacier is largest in Beedle and others (2008), while second largest in our study.

On average, Alaska's glaciers have a length of $1.9 \mathrm{~km}$ and an area of $3.2 \mathrm{~km}^{2}$. Both glacier area and length distributions are strongly left-skewed, yielding median values that are much lower than the means $\left(0.3 \mathrm{~km}^{2}\right.$ and $0.9 \mathrm{~km}$; Fig. 7$)$. Glaciers smaller than the median area account for only $2.2 \%$ of the total glacierized area, while the three largest glacier systems (Malaspina, Bering and Hubbard) comprise $\sim 14 \%$ of the total glacier area.

\section{Area-length relationship}

Area and length typically have a log-log relationship (Bahr and others, 1997). Our analysis of this relationship yields slightly variable fits for the 21 study regions, with the Central Alaska Range (dominated by mountain glaciers) having the longest, and the Kenai Mountains (dominated by ice-field outlet glaciers) having the shortest glaciers with respect to their area. Differences are most pronounced when considering only glaciers above a certain size threshold (e.g. $1 \mathrm{~km}^{2}$ in Fig. 8a). Our derived log-log relationship for all glaciers $\left(1.55 A^{0.647}\right)$ is slightly steeper than the relationship $1.59 A^{0.606}$ of Machguth and Huss (2014), who used a different method of deriving the glacier lengths and a lower minimal size threshold. The two fits intersect at $1.85 \mathrm{~km}^{2}$, with greater lengths of the Machguth and Huss (2014) approach below the intersection. In our case, one single $\log -\log$ fit tends to overestimate the length of the largest glaciers. The overestimation is reduced using two fits, here separated at $10 \mathrm{~km}^{2}$ (Fig. 8b). We note that length and average glacier width also correlate (Fig. 8c). As expected, the correlation coefficients decrease towards smaller glaciers, where a wider range of glacier geometries exists.

Table 4. Summary of the glacierized areas per region

\begin{tabular}{|c|c|c|c|c|c|c|c|c|c|}
\hline \multirow[t]{2}{*}{ Region } & \multicolumn{4}{|c|}{ Number of glaciers larger than } & \multicolumn{3}{|c|}{ Area } & \multicolumn{2}{|c|}{ Length* } \\
\hline & $0.025 \mathrm{~km}^{2}$ & $1 \mathrm{~km}^{2}$ & $10 \mathrm{~km}^{2}$ & $100 \mathrm{~km}^{2}$ & $\begin{array}{c}\text { Total } \\
\mathrm{km}^{2}(\%)\end{array}$ & $\begin{array}{c}\text { Max. } \\
\mathrm{km}^{2}\end{array}$ & $\begin{array}{c}\text { Mean } \\
\mathrm{km}^{2}\end{array}$ & $\begin{array}{c}\text { Max. } \\
\text { km }\end{array}$ & $\begin{array}{r}\text { Mean } \\
\text { km }\end{array}$ \\
\hline 01 Brooks Range & 616 & 83 & 1 & 0 & $345.6(0.4)$ & 12.8 & 0.6 & 8.3 & 1.2 \\
\hline 02 Wood River Mountains & 81 & 9 & 0 & 0 & $36.9(0.04)$ & 6.5 & 0.5 & 4.7 & 0.9 \\
\hline 04 Southern Aleutian Range & 625 & 210 & 34 & 0 & $1528.4(1.76)$ & 79.5 & 2.4 & 19.4 & 1.9 \\
\hline 05 Northern Aleutian Range & 1632 & 358 & 41 & 5 & $2878.5(3.32)$ & 173.2 & 1.8 & 42.1 & 1.6 \\
\hline 06 Western Alaska Range & 1328 & 244 & 23 & 4 & $2264.1(2.61)$ & 341.5 & 1.7 & 45.5 & 1.5 \\
\hline 07 Central Alaska Range & 994 & 188 & 31 & 8 & $3781.3(4.36)$ & 479.5 & 3.8 & 77.9 & 2.0 \\
\hline 08 Eastern Alaska Range & 837 & 183 & 37 & 5 & $2650.9(3.06)$ & 234.6 & 3.2 & 42.7 & 1.9 \\
\hline 09 Talkeetna Mountains & 279 & 58 & 7 & 0 & $346.6(0.4)$ & 56.1 & 1.2 & 14.7 & 1.6 \\
\hline 10 Wrangell Mountains & 994 & 268 & 50 & 9 & $4767.3(5.5)$ & 1028.8 & 4.8 & 84.6 & 2.2 \\
\hline 11 Kodiak Island & 85 & 4 & 0 & 0 & $29.5(0.03)$ & 3.5 & 0.3 & 3.8 & 0.7 \\
\hline 13 Western Chugach Mountains & 2454 & 467 & 76 & 17 & $7530.8(8.68)$ & 773.9 & 3.1 & 56.1 & 1.9 \\
\hline 14 Eastern Chugach Mountains & 1340 & 251 & 27 & 9 & $7806.3(9.0)$ & 3025.1 & 5.8 & 196.8 & 2.0 \\
\hline 15 St Elias Mountains & 3605 & 742 & 113 & 36 & $25266.6(29.13)$ & 3362.7 & 7.0 & 137.0 & 2.1 \\
\hline 16 Glacier Bay & 1721 & 360 & 66 & 19 & $6450.1(7.44)$ & 549.3 & 3.7 & 59.7 & 1.8 \\
\hline 17 Alexander Archipelago & 166 & 17 & 0 & 0 & $78.0(0.09)$ & 7.5 & 0.5 & 3.8 & 0.8 \\
\hline 18 Northeastern Coast Mountains & 2044 & 443 & 52 & 10 & $5116.4(5.9)$ & 521.4 & 2.5 & 59.9 & 1.6 \\
\hline 19 Central Coast Mountains & 3391 & 842 & 78 & 11 & $7716.8(8.9)$ & 612.7 & 2.3 & 57.4 & 1.5 \\
\hline 20 Southwestern Coast Mountains & 2625 & 506 & 46 & 3 & $3235.3(3.73)$ & 142.1 & 1.2 & 25.4 & 1.3 \\
\hline 21 British Columbia Interior & 605 & 80 & 3 & 0 & $364.3(0.42)$ & 14.1 & 0.6 & 7.7 & 1.0 \\
\hline Total & 27109 & 5681 & 757 & 144 & $86722.7(100)$ & 3362.7 & 3.2 & 196.8 & 1.9 \\
\hline
\end{tabular}

*Derived for glaciers $>0.1 \mathrm{~km}^{2}$. 

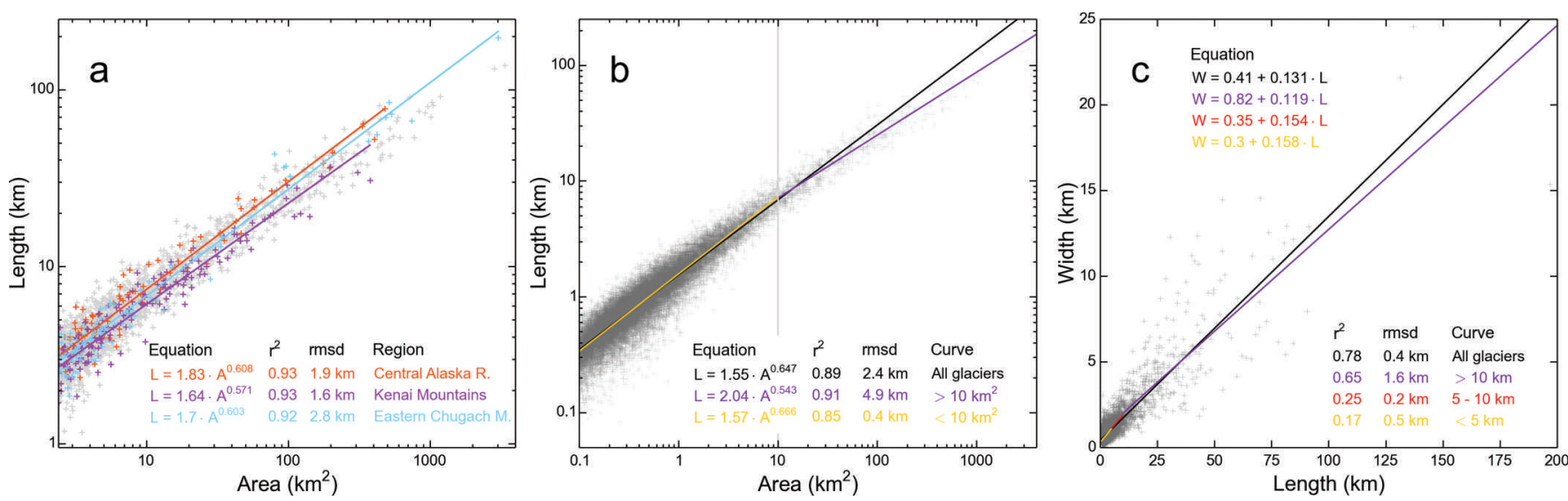

Fig. 8. (a, b) Relation between glacier area and length including best-fit lines for (a) three selected regions (crosses are gray unless part of the selected regions) and (b) all glaciers (black line) as well as for two different size classes (orange and purple) separated at $10 \mathrm{~km}^{2}$. (c) Relation between length and average glacier width with best-fit lines for three length classes separated at 5 and $10 \mathrm{~km}$. All fits are highly significant $(p<0.001)$.

\section{Slope and aspect}

Average slopes, measured along the main center lines, range from $\sim 1^{\circ}$ to $50^{\circ}$, with largest glaciers having the lowest slopes (Fig. 9a). A log-log fit between length and slope explains $\sim 60 \%$ of the variability, with notable outliers. For example, Foraker Glacier in the Central Alaska Range is exceptionally steep for its length $\left(10^{\circ}\right.$ at $\left.24 \mathrm{~km}\right)$. Among the flattest glaciers are the $32 \mathrm{~km}$ long Yakutat Glacier and neighboring Novatak Glacier $(38 \mathrm{~km})$, with slopes of $1.5^{\circ}$ and $1.8^{\circ}$, respectively. Both glaciers drain a low-lying, strongly receding coastal icefield (Trüssel and others, 2013), and their exceptionally low slopes may indicate their limited ability to adapt to climate warming. Figure 9a indicates region- and type-specific differences. For example, the glaciers of the Kenai Mountains tend to be flatter than glaciers in other regions. Also, marine-terminating glaciers tend to be steep compared to other glaciers, especially if they are short. Glaciers have a characteristic slope distribution

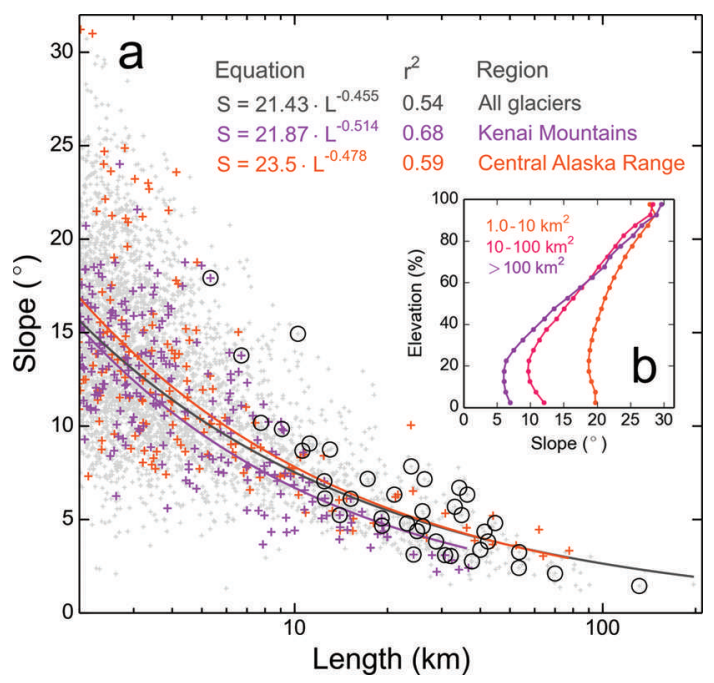

Fig. 9. (a) Glacier slopes measured along center line as a function of length. Length is truncated at $3 \mathrm{~km}$ for better readability. Marineterminating glaciers are marked with black circles. Log-log fits are given for selected regions, including $r^{2}$. Only the abscissa has a logscale. The fits are highly significant $(p<0.001)$. (b) Average gridderived slopes per $5 \%$ elevation bin for three glacier size classes. along their elevation profile (Fig. 9b). Across three distinguished size classes, they are steepest in the highest reaches (90-100\% of their elevation range) and flattest at $\sim 20 \%$ of their elevation range. In the lower reaches of the three size classes, the average slopes vary between $5 \%$ and $20 \%$, which indicates the glaciers' ability to adapt their geometry to climate changes (e.g. Huss, 2012; Harrison, 2013). Lowslope glaciers tend to adapt slowly, thus often having the most negative mass balances under warming conditions.

Northeastern to northwestern aspects dominate the aspect range of the inventory, both in terms of area (areaaspect distribution in Fig. 10) and glacier numbers (Fig. S8 (http://www.igsoc.org/hyperlink/14j230_supp.pdf)). While north-south contrasts are subtle overall, they can be strong for individual regions. For example, the Brooks Range region has $80 \mathrm{~km}^{2}$ in the north-oriented and only $10 \mathrm{~km}^{2}$ in the south-oriented bin. This is likely due to the shortwave radiation that is strongly reduced in north aspects at these high latitudes, and thus an important control on the glacier's mass balance in this continental climate. With its minimum area in west-northwest aspects, the Aleutian Islands region has a notably different area-aspect distribution than the other regions, due to its unique location and topography (volcanic island chain).

Grid-derived vs center-line-derived slopes and aspects Slopes and aspects traditionally derived along the main glacier center line are known to differ substantially from those derived from the full glacier grid. Figure 11a shows
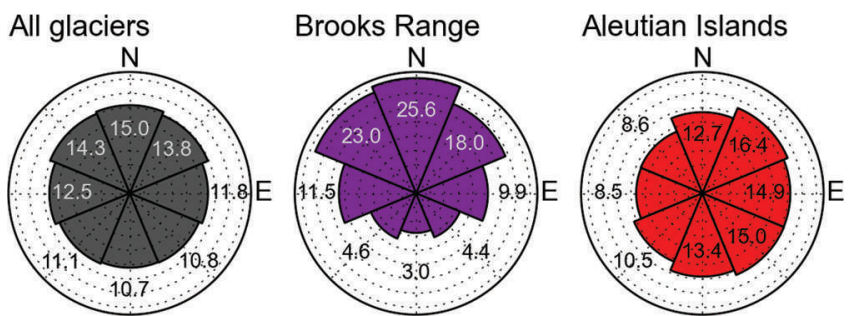

Fig. 10. Area-aspect distribution for the entire study area and two subregions (Brooks Range and Aleutian Islands), using eight aspect bins normalized by area (areas summing up to $100 \%$ ). Annotations give the area percentages per bin. 


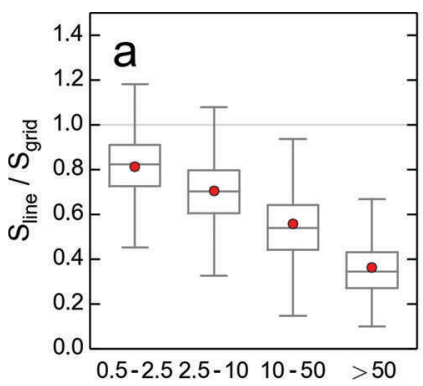

Size class $\left(\mathrm{km}^{2}\right)$

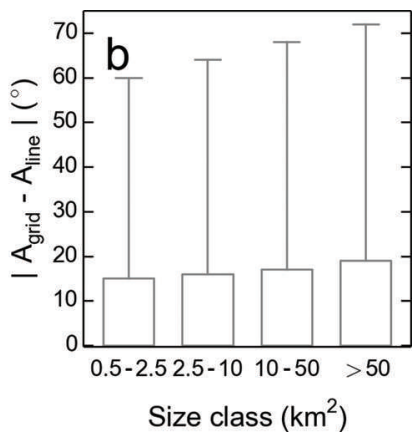

Fig. 11. Agreement of grid- and center-line-derived slopes and aspects for four different size categories. (a) Ratio of center-line- and grid-derived slopes $(S)$. (b) Absolute difference between the grid- and the line-derived aspects $(A)$. The whiskers represent 1.5 times the interquartile range (IQR), and red points show the arithmetic means of the distribution. Outliers are not shown, for improved readability. how our grid-derived slopes compare to the values derived along the main center line, distinguishing four size classes. The differences between the two quantities increase towards larger size classes: for the size category $>10 \mathrm{~km}^{2}$, more than half of the glaciers have grid-derived slopes at least twice as steep as the center-line-derived slopes. Figure $11 \mathrm{~b}$ shows that more than half of the deviations in aspect are within $20^{\circ}$ throughout the four size classes, with outliers that can be substantially higher. Discrepancies are greatest for the largest size class, where glaciers have many, often differently oriented side branches.

\section{Area-altitude distribution}

Glacier ice ranges in elevation from $6165 \mathrm{~m}$ (Mount McKinley, Central Alaska Range) to sea level, reached in seven regions (Fig. 12). The regionally averaged median elevations extend from $975 \mathrm{~m}$ (Kodiak Island) to $2225 \mathrm{~m}$
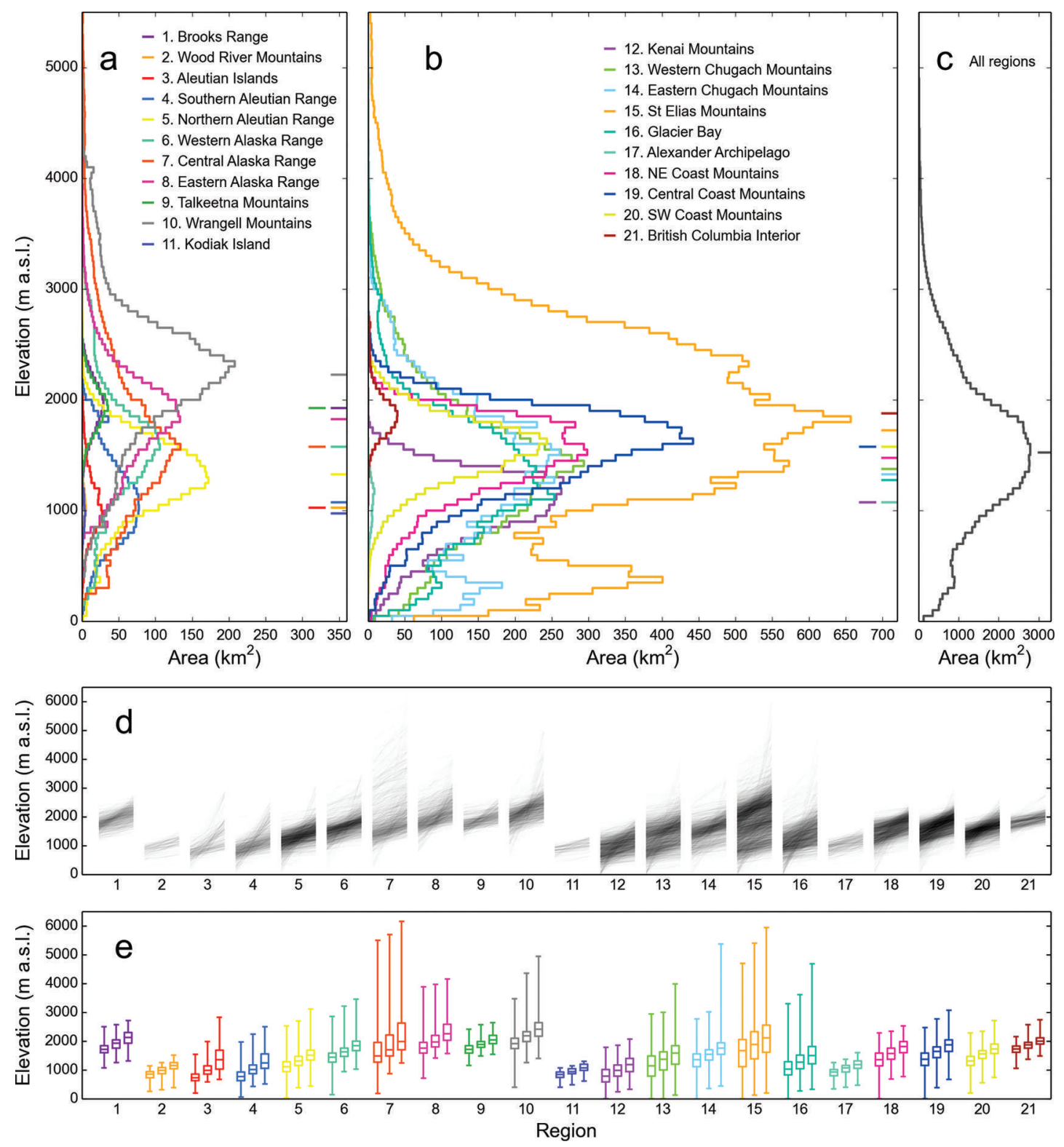

Fig. 12. Hypsometries of the 21 regions. (a-c) Glacier hypsometries in $50 \mathrm{~m}$ bins, per region $(\mathrm{a}, \mathrm{b})$ and for all regions combined (c). Horizontal ticks to the right side of the panel indicate the median elevations of each region. Note that the abscissae are the same in (a) and (b) but differ in (c). (d) Individual glacier hypsometries, with semi-transparent lines connecting the minimum (left), median (middle) and maximum elevations (right) for each glacier of the 21 regions. (e) Summary of (d) using three box plots per region, showing the distribution of minimum, median and maximum glacier elevations. The whiskers represent the full elevation range. 

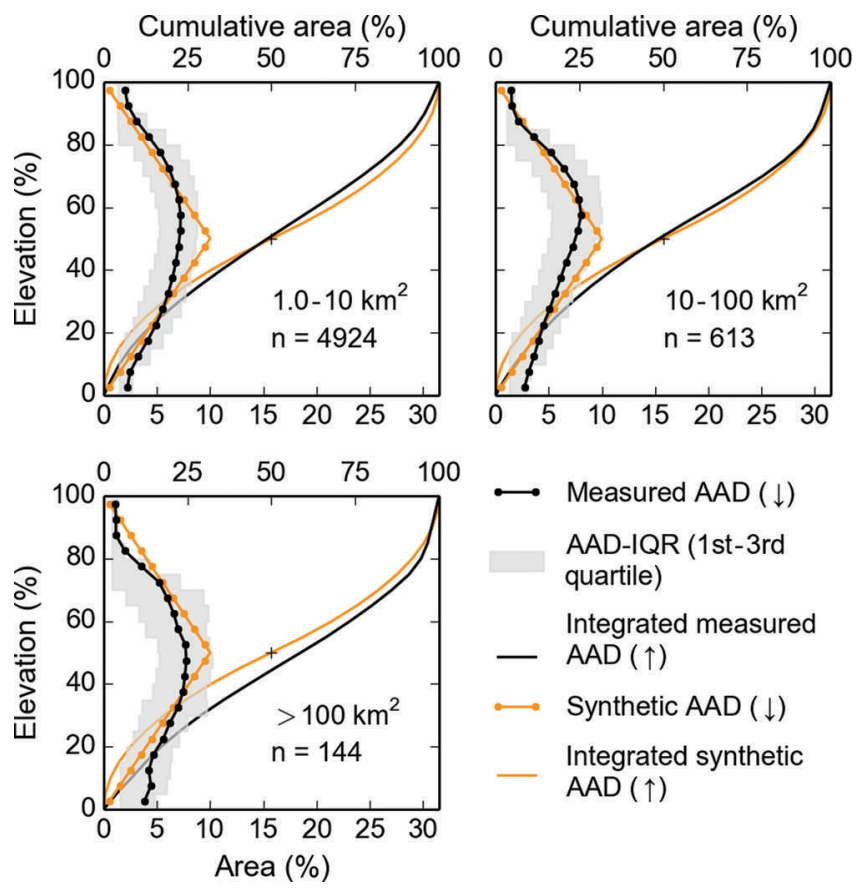

Fig. 13. Normalized area-altitude distributions (AADs). Black dots reflect the average AAD per 5\% elevation bin, and gray shaded areas span between the first and third quartile of the corresponding distribution. The orange dots represent the synthetic mountain glacier $\operatorname{AAD}(s=0, k=-0.6)$ according to Raper and Braithwaite (2006). Solid lines show the cumulative AAD for the two distributions. Arrows in the legend indicate whether the upper or lower axis is used.

(Wrangell Mountains). Regions containing large piedmont glaciers, or spanning multiple subregions of distinct topography and climate, tend to have secondary peaks and plateaus in their hypsometric curves. Overall, only 1960 glaciers $(7.2 \%)$ span elevation differences greater than $1000 \mathrm{~m}$, while smaller glaciers with limited elevation ranges are more abundant (Fig. 12d). Median glacier elevation increases with distance from the coast (Fig. S6a (http://www. igsoc.org/hyperlink/14j230_supp.pdf)). Both the slope of the fit and the corresponding correlations are highest along the coast, leveling off towards the interior, hinting at strong coastal precipitation gradients. Figure S6b and c (http:// www.igsoc.org/hyperlink/14j230_supp.pdf) illustrate precipitation and temperature distributions for the 21 subregions, which are both inversely correlated with the median glacier elevations (Fig. 12e).

\section{Analysis of normalized hypsometries}

Figure 13 illustrates the glacier hypsometries for three size classes, normalized by both area and elevation. The averaged hypsometries have parabolic shapes with area percentages increasing towards the mid-elevations before decreasing towards the termini. While the curve for the smallest size class $\left(1-10 \mathrm{~km}^{2}\right)$ is symmetric, larger glaciers tend to have more area at their lowest elevations. At these low elevations, glaciers are flat (Fig. 9b), indicating potentially high ice thicknesses and thus large ice volumes, which are vulnerable to loss given sustained glacier retreat.

Figure S7 (http://www.igsoc.org/hyperlink/14j230_supp. pdf) illustrates the glacier hypsometries for 18 regions as well as the entire study region, including skewness and kurtosis to quantify the curves' shapes. Of the 18 averaged
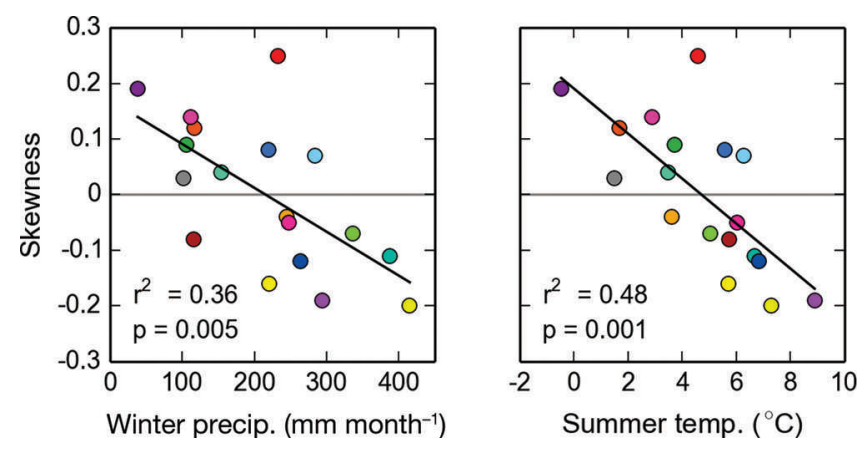

Fig. 14. Linear fits between regionally averaged skewness, winter precipitation and summer temperature. The color code is adopted from Figure 1. $p$ indicates the significance level.

curves, four have a skewness $s$ close to zero $(0 \pm 0.05$, indicating high symmetry), while seven curves each are top$(s<-0.05$, i.e. median elevation $>$ mid-elevation) and bottom-heavy ( $s>0.05$, median elevation $<$ mid-elevation).

We investigate how Alaska's normalized hypsometries compare to the wedge-shaped synthetic hypsometry of Raper and Braithwaite (2006) previously used in mass-balance assessments, due to the lack of adequate glacier inventory data (e.g. Radić and Hock, 2011). Overall, we find that Alaska's glaciers match the wedge-shaped synthetic hypsometry well. Taken as input for mass-balance assessments, our overall measured hypsometry would yield mass changes that are likely similar to those derived from the synthetic hypsometry, as the differences between the hypsometries even out: while the synthetic hypsometry underestimates the areas in both the lowest and highest reaches, it overestimates the areas above and below the mid-elevations. Having more area around the mid-elevations, however, glaciers with synthetic hypsometry may be more susceptible to climate change. While the overall hypsometry closely matches the synthetic hypsometry of Raper and Braithwaite (2006), this does not necessarily apply to individual regions or size classes. For the largest size class in Figure 13, the use of a synthetic hypsometry would bias the modeled mass-balance results towards more positive values as it does not account for the excess area at the lowest elevations. We note that such comparisons always assume that the distributions use the same minimum and maximum elevations.

As the skewness of the normalized hypsometries varies across regions (Fig. S7 (http://www.igsoc.org/hyperlink/ 14j230_supp.pdf)), we investigate how skewness compares to other regionally averaged glacier variables. We find that the symmetry of the averaged hypsometries correlates with the regionally averaged summer temperature at the median elevations as well as the corresponding winter precipitation (Fig. 14), suggesting that glaciers in a more maritime setting might be more top-heavy than glaciers in a continental setting. Rather than indicating direct causation, these correlations may be a proxy for the predominant topography in these climates (steep mountainous topography in the continental parts vs smoother ice-field topography in more coastal areas). We note no significant correlations with other regionally averaged parameters (e.g. debris cover, glacier area).

\section{Glacier type and glacier margin type}

We identify 39 marine-terminating glaciers across five regions, and 148 lake- and river-terminating glaciers across 

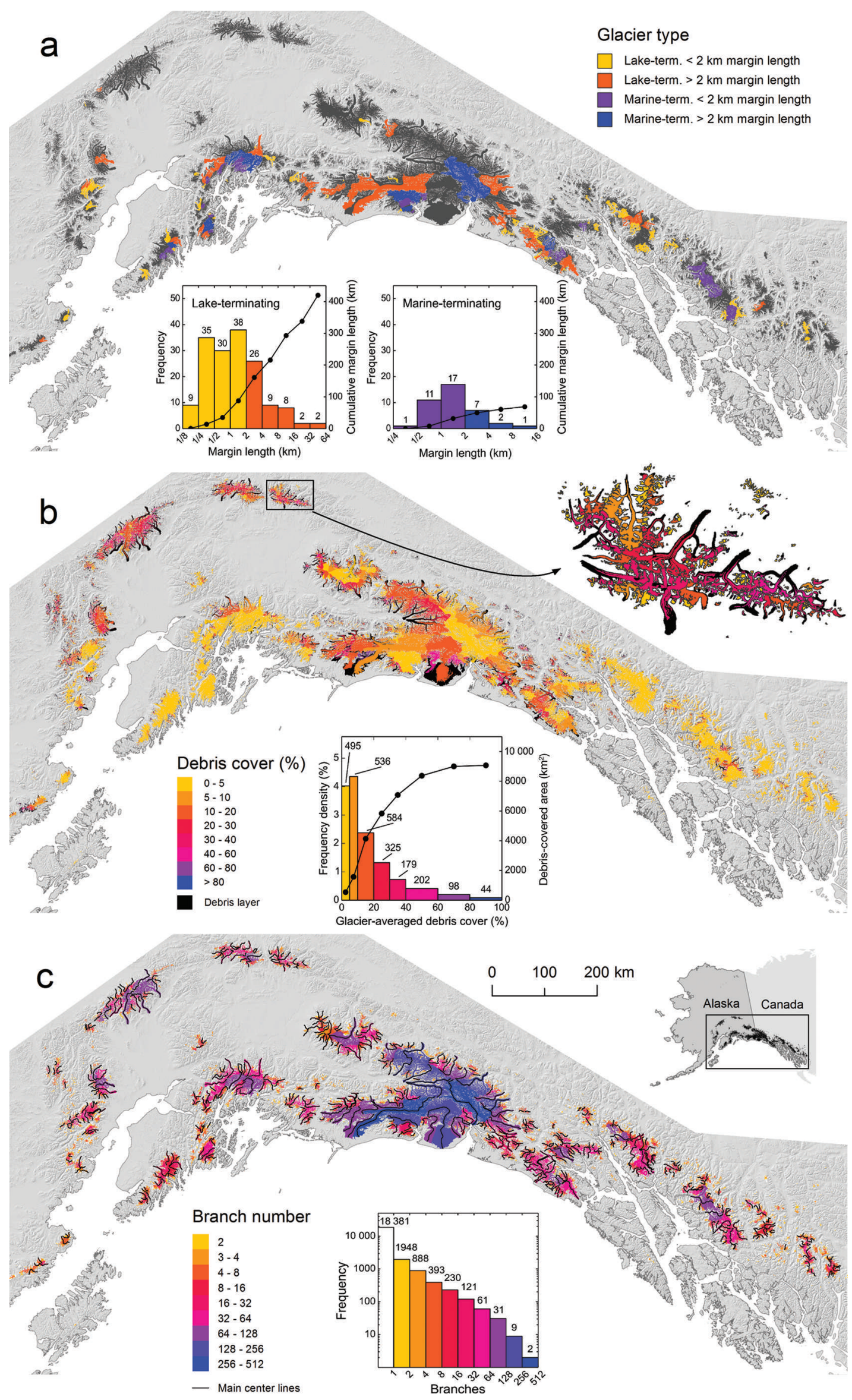

Fig. 15. (a) Marine- and lake-terminating glaciers, each separated in two length categories. The histograms give the numbers of glaciers per margin length bin (left axis) as well as the cumulative margin length (right axis). (b) Glacier-averaged debris cover for southern Alaska, distinguishing eight classes of glacier-averaged debris cover. The inset map shows the glacier-averaged debris cover for the eastern part of the Eastern Alaska Range. The histogram gives the frequency density for each of the eight debris classes, with annotations of the actual numbers per debris class. (c) Map and histogram with branch numbers. Center lines are given for glaciers longer than $10 \mathrm{~km}$. 


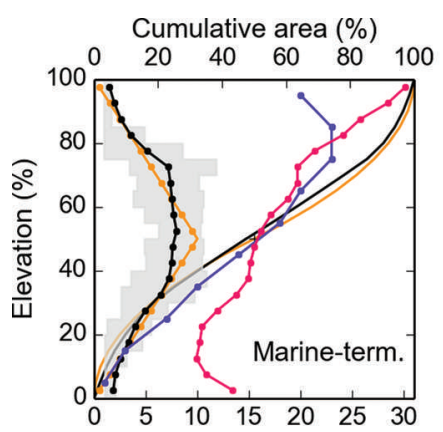

Area $(\%)$, Slope $\left({ }^{\circ}\right)$, Branches

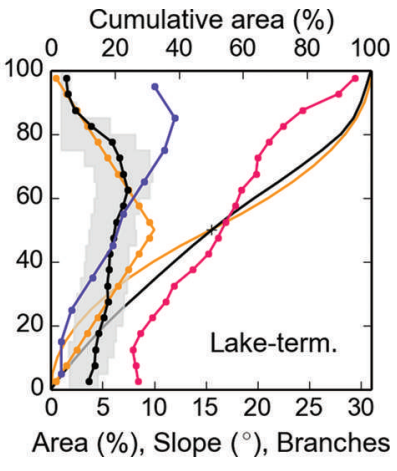

Fig. 16. Normalized glacier area-altitude distributions (AADs) for marine- and lake-terminating glaciers. The black connected dots (lower abscissa) show the averaged AADs, distinguishing 5\% elevation bins. The gray shaded area shows the interquartile range for each $5 \%$ bin. The orange dots represent the synthetic mountain glacier $\operatorname{AAD}(s=0, k=-0.6)$ according to Raper and Braithwaite (2006). Solid lines (upper abscissa) show the cumulative AAD for the two distributions. The purple dots show the average slope per $5 \%$ elevation bin, while the blue dots show the branch number per $10 \%$ elevation bin.

13 regions (Fig. 15a; Table 4). The actual number of glaciers with lake/river termini is higher (159), but 11 of these glaciers are considered land- or marine-terminating overall. With a total area of $10372 \mathrm{~km}^{2}$, marine-terminating glaciers drain $12.0 \%$ of the total glacierized area while laketerminating glaciers $\left(16720 \mathrm{~km}^{2}\right)$ drain $19.3 \%$ of the total glacierized area. The total length of the identified tidewater margins is $74 \mathrm{~km}$, with 27 glaciers having tidewater margins longer than $1 \mathrm{~km}$ (Fig. 15a). Lake- and river-calving margins have a total length of $420 \mathrm{~km}$. The three glaciers of the Bering Glacier system contribute $75 \mathrm{~km}(18 \%)$ of laketerminating margin (Table 4).

Table 5 summarizes selected statistical parameters for the distinguished glacier types. It indicates, for example, that the lake-terminating glaciers' average distance from the coast is $31 \mathrm{~km}$, substantially less than the $67 \mathrm{~km}$ for land-terminating glaciers. This difference is likely related to the high precipitation amounts along the coast, which have allowed glaciers to reach low-lying flat terrain. Flat terrain is particularly susceptible to overdeepened channels and thus lakes upon glacier retreat (e.g. Trüssel and others, 2013).

As expected for their truncated geometries, marineterminating glaciers have low area percentages at their lowest elevations (Fig. 16), which would be atypical for land-terminating glaciers of the same size. Related to the former observation, marine-terminating glaciers are steep close to their termini, having higher slopes in the lowest $20 \%$ of the elevation range than their lake-terminating

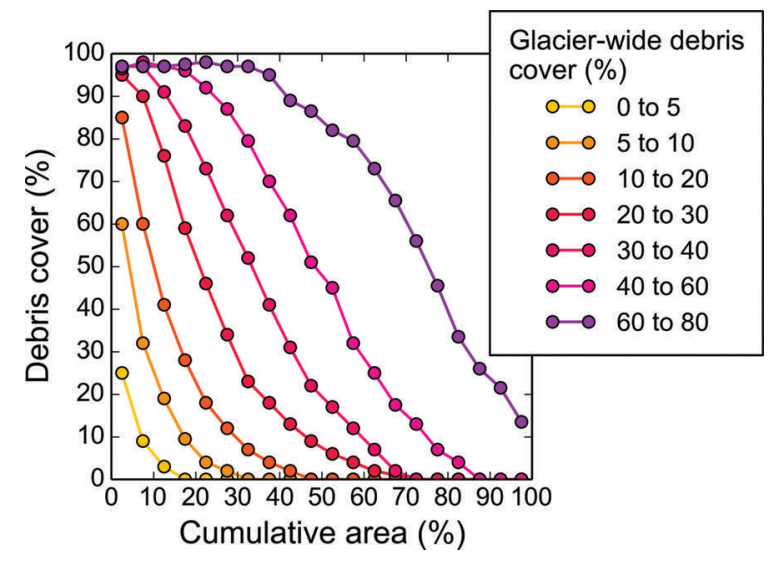

Fig. 17. Percentage debris cover per $5 \%$ area bin for seven classes of glacier-wide debris cover. $0-5 \%$ of the cumulative area corresponds to the lowest $5 \%$ of the glacier.

counterparts. As a controlling factor on ice velocities, surface slopes may have partial control on the glaciers' dynamic mass losses. In agreement with observations, this would suggest lower dynamic losses for lake-terminating than for marine-terminating glaciers.

\section{Debris}

Debris covers $\sim 11 \%$ of the glacierized terrain in Alaska, with percentages that vary substantially among regions (Fig. 15b). With 28\%, region 7 (Central Alaska Range) has the highest debris cover, followed by regions 6 and 8 (Western and Eastern Alaska Range) with 24\% and 22\% debris cover each. With only $1.4 \%$, the Kenai Mountains (region 12) have the lowest debris cover. The distinct differences are attributable to varying geology and glacier types. Ice fields stand out with little debris, as their relatively continuous ice cover with few nunataks effectively suppresses extraglacial debris sources.

The histogram in Figure 15b shows the number of glaciers for eight debris classes, considering the 2463 glaciers larger than $1 \mathrm{~km}^{2}$ and with nonzero overall debris cover. Glaciers with little debris cover $(<10 \%)$ are most abundant, while glaciers with higher debris cover are still common. We note that the decrease in glacier numbers from the $2.5-5 \%$ bin to the $0-2.5 \%$ bin is likely not real, but due to the applied filter (removal of debris patches $<5000 \mathrm{~m}^{2}$ ).

Debris shows a characteristic distribution along the glacier hypsometry, with shapes of the debris curves evolving from concave to convex as a function of the glacier-wide debris cover (Fig. 17). As expected, the highest relative debris cover is found at lowest elevations, with a strong decrease towards higher elevations. Even in the case

Table 5. Statistics for marine-, lake- and land-terminating glaciers. The given values are arithmetic means. Slope term refers to the slope of the lowest $10 \%$ of the glacier area

\begin{tabular}{|c|c|c|c|c|c|c|c|c|c|}
\hline Type & $\begin{array}{l}\text { Area } \\
\mathrm{km}^{2}\end{array}$ & $\begin{array}{l}\text { Distance from coast } \\
\qquad \mathrm{km}\end{array}$ & $\begin{array}{c}\text { Debris cover } \\
\%\end{array}$ & Mean slope & Slope term & $\begin{array}{l}\text { Min. elev. } \\
\text { ma.s.l. }\end{array}$ & $\begin{array}{c}\text { Med. elev. } \\
\text { ma.s.l. }\end{array}$ & $\begin{array}{c}\text { Max. elev. } \\
\text { ma.s.l. }\end{array}$ & $\begin{array}{c}\text { Elev. range } \\
\text { ma.s.l. }\end{array}$ \\
\hline Marine & 265.94 & 12 & 2 & 13.97 & 9.21 & 34 & 1319 & 2714 & 2680 \\
\hline Lake & 112.98 & 31 & 12 & 14.21 & 8.50 & 346 & 1237 & 2193 & 1846 \\
\hline Land & 2.17 & 67 & 17 & 24.09 & 22.99 & 1353 & 1575 & 1802 & 449 \\
\hline
\end{tabular}




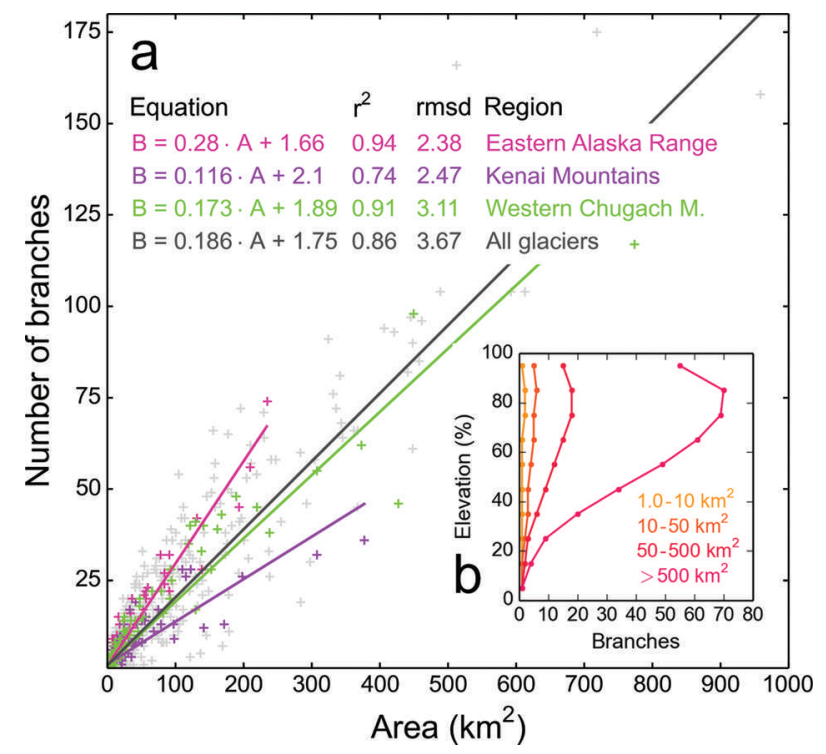

Fig. 18. (a) Correlation between glacier area and branch number. The colored lines show linear fits for selected regions. Only glaciers $<1000 \mathrm{~km}^{2}$ are considered. All the fits are highly significant $(p<0.001)$. (b) Average branch number per $10 \%$ elevation bin for four size classes.

of $<5 \%$ glacier-wide debris cover, the lowest $5 \%$ of the glacier area has a debris cover of $20 \%$.

\section{Branch numbers}

Figure 15c shows the distribution of the branch numbers for the 22064 glaciers $>0.1 \mathrm{~km}^{2}$ for which we calculated center lines. 18381 glaciers (83.3\%) have one branch, while 3683 glaciers $(16.7 \%)$ have at least two branches. The high branch numbers reached (up to 400 for Hubbard Glacier) emphasize the high complexity of the glacier geometries found in our study area.

The number of branches correlates positively with glacier area. A linear fit explains up to $90 \%$ of the variability overall, if the largest glaciers $\left(>1000 \mathrm{~km}^{2}\right)$ are omitted (Fig. 18a), and $\sim 80 \%$ of the variability if we include the largest glaciers. Our fits indicate differences in the areabranch relationship among the subregions: while glaciers in the Kenai Mountains (mostly ice-field outlet glaciers) have $\sim 14$ branches of $100 \mathrm{~km}^{2}$ size, glaciers (typically mountain glaciers) in the Eastern Alaska Range have 30.

Figure $18 \mathrm{~b}$ illustrates the branch numbers as a function of the normalized elevation for four size classes. Small size classes contain only one branch throughout the elevation profile, while larger glaciers have multiple branches, with maximum numbers typically found at $\sim 80-85 \%$ of the glacier elevation range (Fig. 18b). Converging branches towards lower elevations leave one main branch in the lowest-elevation bin.

\section{CONCLUSIONS}

We have created a spatially complete, modern-date glacier inventory for Alaska and neighboring Canada, including $>50$ derived variables across 17 main categories. Our new inventory contains 27109 glaciers, covering $86723 \mathrm{~km}^{2}$ of ice $(\sim 12 \%$ of the global glacierized area, excluding ice sheets). Seward Glacier $\left(3363 \mathrm{~km}^{2}\right.$ area and $137 \mathrm{~km}$ length, the main contributor to the Malaspina piedmont) and Bering Glacier $\left(3025 \mathrm{~km}^{2}, 197 \mathrm{~km}\right)$ are the largest and longest glaciers, respectively. A total of 39 marine-terminating glaciers make up $74 \mathrm{~km}$ of tidewater margin and drain $12.0 \%$ of the total glacierized area, while 148 lake- and river-terminating glaciers make up $420 \mathrm{~km}$ of lake-/river margin and drain $19.3 \%$ of the total glacierized area. For the first time, we have quantified both the length of tidewater and lake-/river margins in Alaska, providing useful input for quantifying mass losses at these margins in the future. Our new debris map shows an overall debris cover of $11 \%$, with considerable differences among regions, ranging from $1.4 \%$ in the Kenai Mountains to $28 \%$ in the Central Alaska Range. Debris cover shows the expected distribution along glacier hypsometry, with highest relative debris cover at lower elevations and a strong decrease towards higher elevations; the characteristic curve shapes vary as a function of the overall debris cover. The derived curves may aid future mass-balance modeling applications.

Comparison between our area-altitude distributions and previously established synthetic hypsometries shows close agreement, corroborating results from previous mass-balance studies; exceptions are larger glaciers (more bottom-heavy) and glaciers close to the coast (more top-heavy). A comparison of grid- and center-line-derived slopes and aspects shows that grid-derived slopes are higher, especially for large glaciers $\left(>10 \mathrm{~km}^{2}\right)$, where half of the grid-derived slopes are at least twice as steep as the line-derived slopes.

Deriving area-length scaling relations indicates that one single log-log fit tends to overestimate the length of the largest glaciers. The overestimation of length is reduced when using two fits, separated at $10 \mathrm{~km}^{2}$ (resulting in a steeper fit for smaller glaciers and a flatter fit for larger glaciers). The fits are slightly variable for the 21 study regions, with the Central Alaska Range (dominated by mountain glaciers) having the longest, and the Kenai Mountains (dominated by ice-field outlet glaciers) having the shortest glaciers with respect to their area.

Comparing $>1600$ glacier outlines derived from IKONOS and Landsat imagery by different investigators yields a total area difference of $\sim 10 \%$, highlighting the difficulty in accurately delineating debris-covered glaciers from optical satellite imagery. Our analysis suggests uncertainties of $\pm 10 \mathrm{~m}$ along clean ice and exceeding $\pm 150 \mathrm{~m}$ along debriscovered margins, which is in approximate agreement with previous studies. Assuming fully correlated errors yields errors of $6 \%$ for all Alaska glaciers, and up to $15 \%$ for individual subregions. These errors are larger than usually reported for regional scales, emphasizing the need for studies that quantify error correlation scales adequately. Applying a downscaling approach indicates that our inventory might miss a large number of glacierets $(>40000)$ due to the applied minimal area threshold of $0.025 \mathrm{~km}^{2}$ and other omission errors. While the potential area contribution of these missed glacierets is small $(\sim 1 \%$ for all of Alaska), it could be substantial for individual regions (e.g. $11 \%$ for the Brooks Range).

The Alaska outline database is a major step forward, providing a spatially complete outline dataset including many attributes that quantify a wide range of glacier properties. Several variables such as outline types, distance grids and debris cover are new for a glacier inventory of this size. Further improvements to the inventory should focus on improved identification of debris-covered glacier parts (e.g. 
aided by radar interferometry). Improved and temporally more consistent DEMs could further reduce uncertainties in the center lines, the glacier divides and the derived parameters. Additional attributes such as the classification of surge-type glaciers could make the database more complete in terms of variables. To accommodate future applications of the inventory, the glacier outlines are available from RGI version 4.0 onwards (http://www.glims. org/RGl/randolph.html).

\section{ACKNOWLEDGEMENTS}

Support for this work was provided by NASA under the Cryosphere Sciences Program (grants NNH10Z1A001N, NNX11AF41G), by the US National Science Foundation (grant EAR-0943742) and the National Park Service (H9911080028). Comments by B. Raup and R. Wheate improved the manuscript.

\section{REFERENCES}

Anderson B and Mackintosh A (2012) Controls on mass balance sensitivity of maritime glaciers in the Southern Alps, New Zealand: the role of debris cover. J. Geophys. Res., 117(F1), F01003 (doi: 10.1029/2011/JF002064)

Arendt, AA, Echelmeyer KA, Harrison WD, Lingle CS and Valentine VB (2002) Rapid wastage of Alaska glaciers and their contribution to rising sea level. Science, 297(5580), 382-386 (doi: 10.1126/science.1072497)

Arendt A and 7 others (2006) Updated estimates of glacier volume changes in the western Chugach Mountains, Alaska, and a comparison of regional extrapolation methods. J. Geophys. Res., 111(F3), F03019 (doi: 10.1029/2005JF000436)

Atwood DK, Meyer F and Arendt A (2010) Using L-band SAR coherence to delineate glacier extent. Can. J. Remote Sens., 36(1), 186-195

Bahr, DB and Radić V (2012) Significant contribution to total mass from very small glaciers. Cryosphere, 6(4), 763-770 (doi: 10.5194/tc-6-763-2012)

Bahr DB, Meier MF and Peckham SD (1997) The physical basis of glacier volume-area scaling. J. Geophys. Res., 102(B9), 20355-20362 (doi: 10.1029/97JB01696)

Barrand NE and Sharp MJ (2010) Sustained rapid shrinkage of Yukon glaciers since the 1957-1958 International Geophysical Year. Geophys. Res. Lett., 37(7), L07501 (doi: 10.1029/ 2009GL042030)

Beedle MJ and 7 others (2008) Improving estimation of glacier volume change: a GLIMS case study of Bering Glacier System, Alaska. Cryosphere, 2(1), 33-51

Berthier E, Schiefer E, Clarke GKC, Menounos B and Rémy F (2010) Contribution of Alaskan glaciers to sea-level rise derived from satellite imagery. Nature Geosci., 3(2), 92-95 (doi: 10.1038/ ngeo737)

Bieniek PA and 14 others (2012) Climate divisions for Alaska based on objective methods. J. Appl. Meteorol. Climatol., 51(7), 12761289

Bliss A, Hock R and Radić V (2014) Global response of glacier runoff to twenty-first century climate change. J. Geophys. Res., 119(4), 717-730 (doi: 10.1002/2013JF002931)

Bolch T, Menounos B and Wheate R (2010) Landsat-based inventory of glaciers in western Canada, 1985-2005. Remote Sens. Environ., 114(1), 127-137 (10.1016/j.rse.2009.08.015)

Braithwaite RJ and Raper SCB (2007) Glaciological conditions in seven contrasting regions estimated with the degree-day model. Ann. Glaciol., 46, 297-302

Braithwaite RJ and Raper SCB (2010) Estimating equilibrium-line altitude (ELA) from glacier inventory data. Ann. Glaciol., 50(53), $127-132$
Burgess EW, Forster RR, Larsen CF and Braun M (2012) Surge dynamics on Bering Glacier, Alaska, in 2008-2011. Cryosphere, 6(6), 1251-1262

Burgess EW, Forster RR and Larsen CF (2013) Flow velocities of Alaskan glaciers. Nature Commun., 4, 2146 (doi: 10.1038/ ncomms3146)

Cogley JG and 10 others (2011) Glossary of glacier mass balance and related terms. (IHP-VII Technical Documents in Hydrology No. 86, IACS Contribution No. 2) UNESCO-International Hydrological Programme, Paris

Daly C, Neilson RP and Phillips DL (1994) A statistical-topographic model for mapping climatological precipitation over mountainous terrain. J. Appl. Meteorol., 33(2), 140-158 (doi: 10.1175/ 1520-0450(1994)033<0140:ASTMFM>2.0.CO;2)

Farr TG and 17 others (2007) The Shuttle Radar Topography Mission. Rev. Geophys., 45(2), 1-33 (doi: 10.1029/2005RG000183)

Field WO ed. (1975) Mountain glaciers of the Northern Hemisphere, 2 vols. Cold Regions Research and Engineering Laboratory, Hanover, $\mathrm{NH}$

Franke R (1982) Smooth interpolation of scattered data by local thin plate splines. Comput. Math. Appl., 8(4), 273-281

Frey $\mathrm{H}$ and Paul $\mathrm{F}$ (2012) On the suitability of the SRTM DEM and ASTER GDEM for the compilation of topographic parameters in glacier inventories. Int. J. Appl. Earth Obs. Geoinfo., 18, 480490 (doi: 10.1016/j.jag.2011.09.020)

Frey H, Paul F and Strozzi T (2012) Compilation of a glacier inventory for the western Himalayas from satellite data: methods, challenges, and results. Remote Sens. Environ., 124, 832-843 (doi: 10.1016/j.rse.2012.06.020)

Geck J, Hock R and Nolan M (2013) Geodetic mass balance of glaciers in the Central Brooks Range, Alaska, USA, from 1970 to 2001. Arct. Antarct. Alp. Res., 45(1), 29-38 (doi: 10.1657/19384246-45.1.29)

Harrison WD (2013) How do glaciers respond to climate? Perspectives from the simplest models. J. Glaciol., 59(217), 949-960

Huss M (2012) Extrapolating glacier mass balance to the mountainrange scale: the European Alps 1900-2100. Cryosphere, 6(4), 713-727 (doi: 10.5194/tc-6-713-2012)

Kääb A, Berthier E, Nuth C, Gardelle J and Arnaud Y (2012) Contrasting patterns of early twenty-first-century glacier mass change in the Himalayas. Nature, 488(7412), 495-498 (doi: 10.1038/nature11324)

Kienholz C, Hock R and Arendt AA (2013) A new semi-automatic approach for dividing glacier complexes into individual glaciers. J. Glaciol., 59(217), 925-937

Kienholz C, Rich JL, Arendt AA and Hock R (2014) A new method for deriving glacier center lines applied to glaciers in Alaska and northwest Canada. Cryosphere, 8(2), 503-519

Korona J, Berthier E, Bernard M, Rémy F and Thouvenot E (2009) SPIRIT. SPOT 5 stereoscopic survey of Polar Ice: reference images and topographies during the fourth International Polar Year (2007-2009). ISPRS J. Photogramm. Remote Sens., 64(2), 204-212

Krumwiede, BS, Kamp U, Leonard GJ, Kargel JS, Dashtseren A and Walther M (2014) Recent glacier changes in the Mongolian Altai Mountains: case studies from Munkh Khairkhan and Tavan Bogd. In Kargel JS, Leonard GJ, Bishop MP, Kääb A and Raup $\mathrm{BH}$ eds Global Land Ice Measurements from Space. Springer Praxis Books, Berlin and Heidelberg, 481-508

Larsen CF, Motyka RJ, Arendt AA, Echelmeyer KA and Geissler PE (2007) Glacier changes in southeast Alaska and northwest British Columbia and contribution to sea level rise. J. Geophys. Res., 112(F1), F01007 (doi: 10.1029/2006JF000586)

Le Bris R, Paul F, Frey H and Bolch T (2011) A new satellite-derived glacier inventory for western Alaska. Ann. Glaciol., 52(59), 135-143 (doi: 10.3189/172756411799096303)

Loso M, Arendt A, Larsen CF, Rich JL and Murphy N (in press) Alaskan National Park glaciers: status and trends. (Tech. rep.) National Park Service, Fort Collins, CO 
Machguth $\mathrm{H}$ and Huss M (2014) The length of the world's glaciers a new approach for the global calculation of center lines. Cryosphere, 8(5), 1741-1755

Marzeion B, Jarosch AH and Hofer M (2012) Past and future sealevel change from the surface mass balance of glaciers. Cryosphere, 6(6), 1295-1322 (doi: 10.5194/tc-6-1295-2012)

McGrath DA and 7 others (2013) Comparison of annual accumulation rates derived from in situ and ground penetrating radar methods across Alaskan glaciers. AGU Fall Meet. Abstr. C21B0633

McNabb RW and Hock R (2014) Alaska tidewater glacier terminus positions, 1948-2012. J. Geophys. Res., 119(2), 153-167

Meier MF and Post A (1987) Fast tidewater glaciers. J. Geophys. Res., 92(B9), 9051-9058

Molnia BF (2008) Glaciers of North America - Glaciers of Alaska. In Williams RS Jr and Ferrigno JG eds Satellite image atlas of glaciers of the world. US Geol. Surv. Prof. Pap. 1386-J

Nuth C and 7 others (2013) Decadal changes from a multi-temporal glacier inventory of Svalbard. Cryosphere, 7(5), 1603-1621 (doi: 10.5194/tc-7-2489-2013)

Paul F, Huggel C and Kääb A (2004) Combining satellite multispectral image data and a digital elevation model for mapping debris-covered glaciers. Remote Sens. Environ., 89(4), 510-518

Paul F and 9 others (2009) Recommendations for the compilation of glacier inventory data from digital sources. Ann. Glaciol., 50(53), 119-126 (10.3189/172756410790595778)

Paul F and 19 others (2013) On the accuracy of glacier outlines derived from remote-sensing data. Ann. Glaciol., 54(63), 171-182 (doi: 10.3189/2013AoG63A296)

Pfeffer WT and 18 others (2014) The Randolph Glacier Inventory: a globally complete inventory of glaciers. J. Glaciol., $\mathbf{6 0}(221)$, 537-552 (doi: 10.3189/2014JoG13J176)

Radić V and Hock R (2010) Regional and global volumes of glaciers derived from statistical upscaling of glacier inventory data. J. Geophys. Res., 115(F1), F01010 (doi: 10.1029/2009JF001373)

Radić V and Hock R (2011) Regionally differentiated contribution of mountain glaciers and ice caps to future sea-level rise. Nature Geosci., 4(2), 91-94 (doi: 10.1038/ngeo1052)

Radić V, Bliss A, Beedlow C, Hock R, Miles E and Cogley JG (2013) Regional and global projections of twenty-first century glacier mass changes in response to climate scenarios from global climate models. Climate Dyn., 42(1-2), 37-58 (doi: 10.1007/ s00382-013-1719-7)
Raper SCB and Braithwaite RJ (2006) Low sea level rise projections from mountain glaciers and icecaps under global warming, Nature, 439(7074), 311-313 (doi: 10.1038/ nature04448)

Raup B and Khalsa SJS (2007) GLIMS data analysis tutorial. Global Land Ice Measurements from Space

Raup B and 11 others (2007) Remote sensing and GIS technology in the Global Land Ice Measurements from Space (GLIMS) Project. Comput. Geosci., 33(1), 104-125 (doi: 10.1016/j.cageo. 2006.05.015)

Reid TD and Brock BW (2010) An energy-balance model for debriscovered glaciers including heat conduction through the debris layer. J. Glaciol., 56(199), 903-916

Rivera A, Benham T, Casassa G, Bamber J and Dowdeswell JA (2007) Ice elevation and areal changes of glaciers from the Northern Patagonia Icefield, Chile. Clobal Planet. Change, 59(1), 126-137

Schiefer E, Menounos B and Wheate R (2008) An inventory and morphometric analysis of British Columbia glaciers, Canada. J. Glaciol., 54(186), 551-560 (doi: 10.3189/ 002214308785836995)

Sevestre H, Benn D and Hagen J (2013) A geodatabase on surgetype glaciers: behaviours, trends and clustering. AGU Fall Meet. Abstr. C33A-0683

Shulski M and Wendler G (2007) The climate of Alaska. University of Alaska Press, Fairbanks, AK

Tachikawa T, Hato M, Kaku M and Iwasaki A (2011) Characteristics of ASTER GDEM version 2. In IGARSS 2011, International Geoscience and Remote Sensing Symposium, 24-29 July 2011, Vancouver, Canada. Proceedings. International Institute of Electrical and Electronics Engineers, Picataway, NJ, 36573660 (doi: 10.1109/IGARSS.2011.6050017)

Trüssel BL, Motyka RJ, Truffer M and Larsen CF (2013) Rapid thinning of lake-calving Yakutat Glacier and the collapse of the Yakutat Icefield, southeast Alaska, USA. J. Glaciol., 59(213), 149-161 (doi: 10.3189/2013JoG12J081)

Williams RS Jr, Hall DK, Sigurdsson O and Chien JYL (1997) Comparison of satellite-derived with ground-based measurements of the fluctuations of the margins of Vatnajökull, Iceland, 1973-92. Ann. Glaciol., 24, 72-80

Winsvold SH, Andreassen LM and Kienholz C (2014) Glacier area and length changes in Norway from repeat inventories. Cryosphere, 8(5), 1885-1903 (doi: 10.5194/tc-8-1885-2014) 